\title{
Root-emitted volatile organic compounds: can they mediate belowground plant-plant interactions?
}

\author{
Benjamin M. Delory • Pierre Delaplace • \\ Marie-Laure Fauconnier • Patrick du Jardin
}

Received: 14 November 2015 / Accepted: 29 January 2016/Published online: 12 February 2016

(C) Springer International Publishing Switzerland 2016

\begin{abstract}
Background Aboveground, plants release volatile organic compounds (VOCs) that act as chemical signals between neighbouring plants. It is now well documented that VOCs emitted by the roots in the plant rhizosphere also play important ecological roles in the soil ecosystem, notably in plant defence because they are involved in interactions between plants, phytophagous pests and organisms of the third trophic level. The roles
\end{abstract}

Responsible Editor: Philippe Hinsinger.

B. M. Delory · P. Delaplace · P. du Jardin $(\bowtie)$

Plant Biology, Gembloux Agro-Bio Tech, University of Liège,

Passage des Déportés, 2, 5030 Gembloux, Belgium

e-mail: Patrick.duJardin@ulg.ac.be

\section{B. M. Delory}

e-mail: Benjamin.Delory@leuphana.de

P. Delaplace

e-mail: Pierre.Delaplace@ulg.ac.be

\section{B. M. Delory}

Ecosystem Functioning and Services, Institute of Ecology,

Leuphana University, Scharnhorststrasse, 1, 21335 Lüneburg,

Germany

\section{M.-L. Fauconnier}

General and Organic Chemistry, Gembloux Agro-Bio Tech, University of Liège, Passage des Déportés, 2, 5030 Gembloux, Belgium

e-mail: Marie-Laure.Fauconnier@ulg.ac.be

\section{M.-L. Fauconnier}

Volatolomics Laboratory, Gembloux Agro-Bio Tech, University of Liège, Passage des Déportés, 2, 5030 Gembloux, Belgium played by root-emitted VOCs in between- and withinplant signalling, however, are still poorly documented in the scientific literature.

Scope Given that (1) plants release volatile cues mediating plant-plant interactions aboveground, (2) roots can detect the chemical signals originating from their neighbours, and (3) roots release VOCs involved in biotic interactions belowground, the aim of this paper is to discuss the roles of VOCs in between- and withinplant signalling belowground. We also highlight the technical challenges associated with the analysis of root-emitted VOCs and the design of experiments targeting volatile-mediated root-root interactions.

Conclusions We conclude that root-root interactions mediated by volatile cues deserve more research attention and that both the analytical tools and methods developed to study the ecological roles played by VOCs in interplant signalling aboveground can be adapted to focus on the roles played by root-emitted VOCs in between- and within-plant signalling.

Keywords Plant-plant signalling · Volatile organic compounds (VOCs) · Plant root volatile emission . Rhizosphere $\cdot$ Root-root interactions

\section{Introduction}

In nature, plants continuously interact with other living organisms that share their environment, notably via the synthesis and release of volatile organic compounds (VOCs). VOCs can be produced by various plant organs 
(leaves, flowers, fruits and roots) and have been shown to be key mediators in biotic interactions both aboveground and belowground (Dudareva et al. 2006; Peñuelas et al. 2014) (Fig. 1). VOCs produced by plants aboveground are dominated by four chemical families originating from the following biosynthetic pathways: terpenoids (mevalonic acid [MVA] and methylerythritol phosphate [MEP] pathways); fatty acid derivatives (lipoxygenase [LOX] pathway); benzenoid and phenylpropanoid compounds (shikimic acid pathway); and amino acid derivatives (Maffei 2010; Baldwin 2010; Dudareva et al. 2013). These compounds are low molecular weight molecules that can be emitted either constitutively (e.g., floral volatiles attracting pollinators) or in response to biotic (Dudareva et al. 2006; Unsicker et al. 2009; Rasmann et al. 2012; Dudareva et al. 2013) or abiotic stress (Gouinguené and Turlings 2002; Loreto and Schnitzler 2010). Because they can be toxic for plant pathogens (Holopainen 2004; Matsui et al. 2006) and are able to repel insect herbivores (De Moraes et al. 2001), these compounds can act in direct plant defences against pests. In addition, because they are able to attract organisms of the third trophic level (parasitoids, entomopathogenic nematodes, etc.) both aboveground (Turlings et al. 1990; De Moraes et al. 1998) and belowground (Rasmann et al. 2005), they are also involved in indirect plant defences. Once released into the air surrounding a plant, VOCs can be perceived by other parts of the same plant (Heil and Silva Bueno 2007; Frost et al. 2007) or by proximate neighbours that eavesdrop on the volatile signals emitted by a damaged plant (Karban et al. 2000). In response to the volatile blends released by emitters, receivers can start expressing genes and synthesise secondary metabolites involved in plant defences (Shulaev et al. 1997; Arimura et al. 2000a; Sugimoto et al. 2014) or can prime their defences against pests (Engelberth et al. 2004; Ton et al. 2006; Heil and Kost 2006), suggesting that VOCs play key roles in mediating within- and between-plant signalling aboveground (Heil and Ton 2008; Heil and Karban 2010) (Fig. 2).

As plants growing next to each other compete for light aboveground and for heterogeneously distributed resources (water and nutrients) belowground, they use specific signals to detect the presence of neighbours and adjust their growth accordingly. Aboveground, both the variations in red/far-red and blue light levels in the plant's canopy detected by photoreceptors (phytochromes and cryptochromes) (Ballaré 1999) and the volatile compounds emitted by plants in the atmosphere
(Ninkovic 2003; Pierik et al. 2003) are signals that enable plants to detect the presence of proximate neighbours. With regard to the use of volatile cues, it has been shown that tobacco plants must be able to perceive the phytohormone ethylene in order to develop a shadeavoidance phenotype (Pierik et al. 2003), and that barley plants allocated significantly more biomass to their roots when they were exposed to the volatiles emitted by undamaged conspecifics belonging to another cultivar (Ninkovic 2003). In addition, airborne volatile blends can help parasitic plants (Cuscuta pentagona Engelm.) to select and locate a suitable host (Runyon et al. 2006).

Belowground, root systems can exchange carbon and defence-related signals through common mycorrhizal networks (Simard et al. 1997; Song et al. 2010; Johnson and Gilbert 2015). Plants also release a wide array of molecules via root exudation in the rhizosphere that play numerous roles, particularly in plant nutrition and biotic interactions between plant roots and soil organisms (Bertin et al. 2003; Walker et al. 2003; Haichar et al. 2014; Zhang et al. 2015). Depending on their size, these molecules can be divided into two classes of compounds: low molecular weight (amino acids, organic acids, sugars, phenolics and various other secondary metabolites) and high molecular weight (polysaccharides and proteins) exudates (Walker et al. 2003; Haichar et al. 2014). Once released by plant roots into the rhizosphere, some of these molecules can have negative (phytotoxins, autoinhibition, development of associations with parasitic plants) or positive effects (resistance to herbivores and root detection) on neighbouring plants and can affect plant growth directly (production of phytotoxins) or indirectly (alteration of soil chemistry, microbial populations and nutrient availability) (Inderjit and Weiner 2001; Perry et al. 2007; Weston et al. 2012; Zeng 2014). It is now well documented that roots are able to synthesise and release volatile compounds in the rhizosphere and that VOCmediated interactions also occur belowground between plant roots and soil organisms (Wenke et al. 2010; Peñuelas et al. 2014). Most studies of belowground VOC-mediated biotic interactions, however, have focused on interactions between plants and organisms of higher trophic levels (herbivorous insects, entomopathogenic nematodes, etc.) (Rasmann et al. 2012; Peñuelas et al. 2014) and only a few research papers have dealt with VOC-mediated plant-plant interactions belowground (Ens et al. 2009; Jassbi et al. 2010; Rasmann et al. 2012) (Fig. 2). This is surprising because 
Fig. 1 Overview of the bitrophic and tritrophic interactions mediated by VOCs emitted by plants above and below the soil surface. Plant VOCs can have antimicrobial/antifungal properties against phytopathogens (1). Aboveground, floral and fruit VOCs are known to attract pollinators and seed dispersers. In addition, VOCs emitted by attacked leaves can attract/repel plant pests and attract the natural enemies of the attacking herbivores. Belowground, root VOCs can attract plant pests (insect herbivores and parasitic nematodes) and organisms of the third trophic level that will prey on/feed on herbivores (entomopathogenic nematodes [EPNs], parasitoids/predators). +, attraction; -, repellence; solid arrows, VOC emission; red arrows, interactions between plants and phytophagous pests; blue arrows, interactions between plants and organisms of the third trophic level; dashed arrows, feed on/prey on (Drawing: Ir Carolina

Levicek)

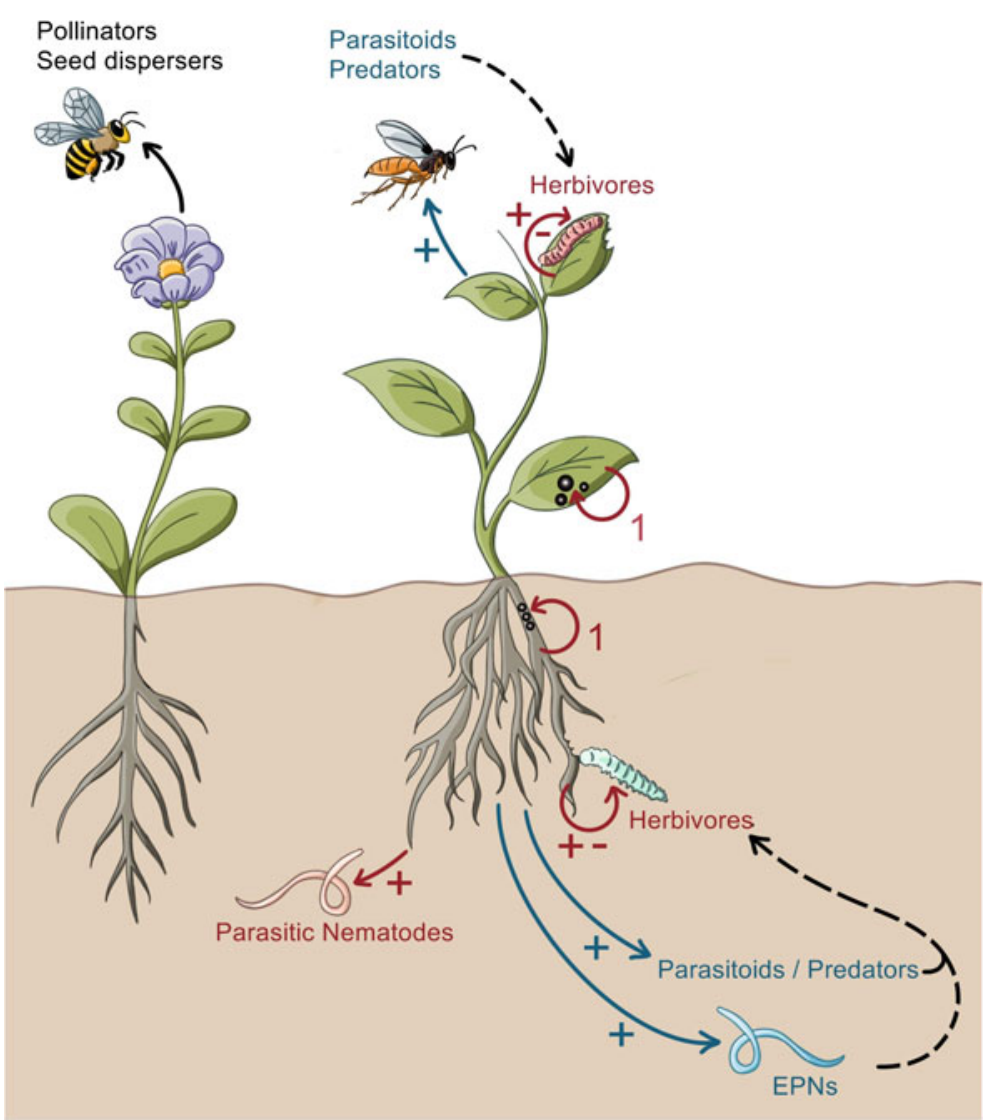

known root-emitted VOC classes, such as terpenes and $\mathrm{C}_{6}$-volatiles derived from the LOX pathway emitted by damaged plant leaves, have been shown to induce physiological and molecular responses in neighbouring plants (Bate and Rothstein 1998; Arimura et al. 2000a, 2001; Ton et al. 2006).

Given that (1) plants emit volatile cues involved in plant-plant signalling aboveground, (2) roots can detect the chemical signals originating from their neighbours, and (3) roots release VOCs mediating belowground biotic interactions, the objective of this review paper is to discuss the roles of VOCs in belowground plant-plant interactions and highlight the technical challenges associated with the analysis of root-emitted VOCs and the design of experiments for studying VOC-mediated root-root interactions.

\section{VOCs play important ecological roles in plant-plant interactions aboveground}

The roles played by VOCs emitted by aboveground plant organs in biotic interactions between neighbouring plants have been extensively reviewed (Dicke and Bruin 2001; Farmer 2001; Heil and Karban 2010; Arimura et al. 2010; Holopainen and Blande 2012; Karban et al. 2014b). Briefly, the emission of an airborne volatile cue by insect-attacked or mechanically damaged trees changing the leaf chemistry of undamaged neighbours was first hypothesized in 1983 in two independent reports (Baldwin and Schultz 1983; Rhoades 1983). Two years later, the controversial debate on 'talking trees' opened with criticisms of the statistical flaws in Baldwin and Schultz's study, as well as the existence of an alternative explanation for Rhoades' results (Fowler and Lawton 1985; Bruin et al. 1995). Since 1983, numerous experiments performed under laboratory and field conditions have shown that VOCs emitted by damaged or undamaged aboveground plant parts of monocotyledonous and dicotyledonous plant species play important roles in interactions between neighbouring plants (Heil and Karban 2010; Karban et al. 2014b) or between different parts of the same plant (Karban et al. 2006; Heil and Silva Bueno 2007; Frost et al. 2007; Park et al. 2007) (Fig. 2). Volatile compounds 


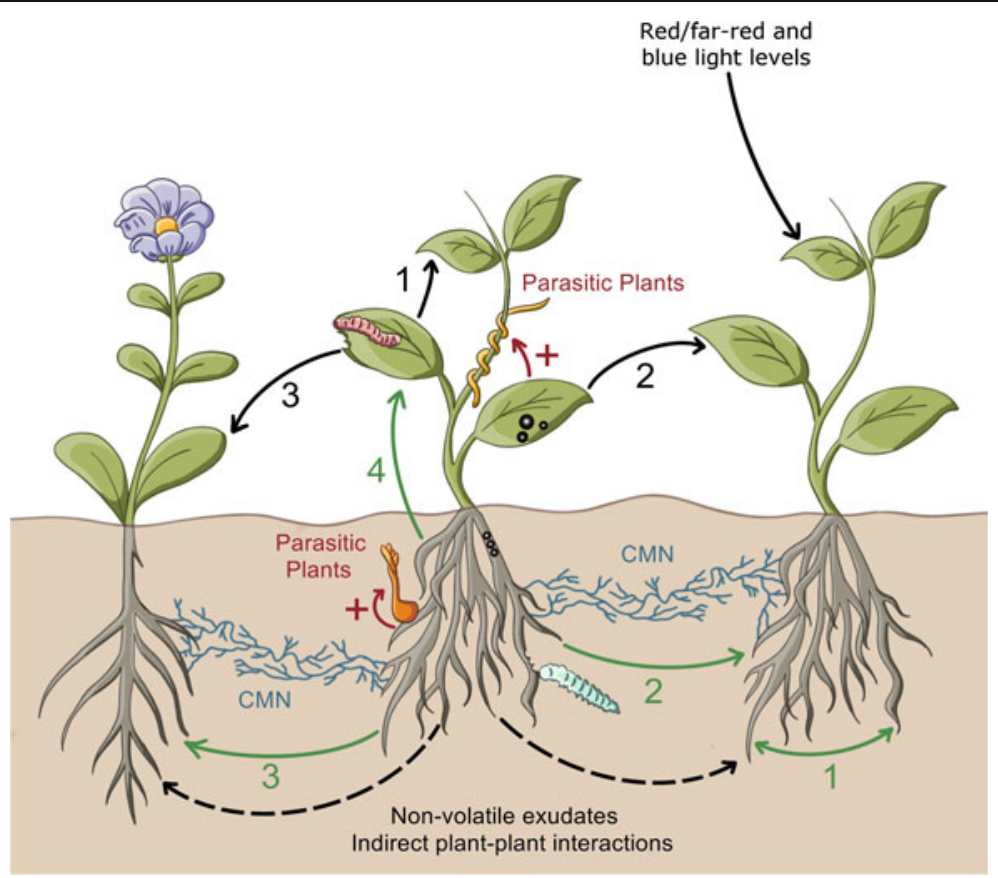

Fig. 2 Overview of the known and potential mechanisms mediating plant-plant interactions above and below the soil surface. Aboveground, both the variations in red/far-red and blue light levels in the plant's canopy and the volatile compounds emitted by plants in the atmosphere enable plants to detect the presence of neighbours. Laboratory and field experiments have also shown that VOCs are involved in within-plant and between-plant signalling aboveground. Belowground, plant-plant interactions mediated by non-volatile exudates, the transport of compounds through common mycorrhizal networks $(\mathrm{CMN})$, and indirect plant-plant

emitted by conspecifics or originating from individuals belonging to another plant species have been shown to promote the induction of direct and indirect defences in undamaged neighbouring plants (Dicke et al. 2003; Heil and Karban 2010), thus increasing their resistance to insect herbivores (Karban et al. 2000; Tscharntke et al. 2001; Karban et al. 2003, 2004; Rodriguez-Saona et al. 2009) or phytopathogens (Shulaev et al. 1997; Yi et al. 2009; Girón-Calva et al. 2012). Volatiles emitted by mechanically damaged or herbivore-attacked plants have also been shown to be able to prime neighbouring plants or parts of the same plant for faster and greater responsiveness to subsequent mechanical stress or herbivore attack, enabling the receiver plants to respond more efficiently when they are attacked (Engelberth et al. 2004; Ton et al. 2006; Heil and Kost 2006; Frost et al. 2007, 2008b; Li et al. 2012; Erb et al. 2015).

With regard to the induction of direct defences, volatile-induced changes reported to date in receiver interactions (alteration of soil chemistry, microbial populations and nutrient availability) have also been reported in the literature. The green arrows refer to plant-plant interactions mediated by root VOCs. 1, within-plant signalling (shoot-shoot or root-root); 2, intraspecific between-plant signalling (shoot-shoot or root-root); 3 , interspecific between-plant signalling (shoot-shoot or root-root); 4, within-plant root-shoot signalling; + , attraction of parasitic plants; solid and labelled arrows, VOC emission (Drawing: Ir Carolina Levicek)

plants include the transcriptional regulation of genes (Farmer et al. 1992; Shulaev et al. 1997; Bate and Rothstein 1998; Arimura et al. 2000a, b, 2001, 2002; Paschold et al. 2006; Godard et al. 2008), and the production of defensive proteins (Farmer and Ryan 1990; Karban et al. 2000; Tscharntke et al. 2001) and phytohormones (ethylene, jasmonic and salicylic acids) (Shulaev et al. 1997; Arimura et al. 2002; Engelberth et al. 2004; Rodriguez-Saona et al. 2009). Interestingly, VOCs emitted by an insect-damaged plant can also be taken from the air and transformed by an undamaged neighbour into a defensive secondary metabolite that will reduce the effect of insect pests feeding on the exposed plants. For instance, it has been shown that undamaged tomato plants are able to produce a defensive glycoside ([Z]-hex-3-enyl-vicianoside) derived from (Z)-hex-3-en-1-ol emitted by conspecifics infested with Spodoptera litura larvae (Sugimoto et al. 2014). Indirect defence mechanisms promoted by volatile cues include the emission of VOCs (Birkett et al. 2000; Farag 
and Paré 2002; Engelberth et al. 2004; Choh et al. 2004; Ruther and Kleier 2005; Yan and Wang 2006; WendaPiesik et al. 2010) and the secretion of extra floral nectar (Kost and Heil 2006; Choh and Takabayashi 2006; Heil and Silva Bueno 2007; Li et al. 2012) leading to the attraction of insects of the third trophic level.

In addition to plant defences, volatile cues emitted by damaged leaves can inhibit the germination of neighbours, thus affecting the plant community structure (Karban 2007). After plant establishment, volatile compounds released by undamaged plants can also be used for the detection of competing neighbours (Ninkovic 2003; Pierik et al. 2003; Kegge et al. 2015). Volatile compounds released by undamaged plants also affect the attractiveness of neighbours to insect herbivores and insect natural enemies. Fewer aphids (Pettersson et al. 1999; Glinwood et al. 2004; Ninkovic et al. 2009) and more aphid natural enemies (ladybirds and parasitoids) (Ninkovic and Pettersson 2003; Glinwood et al. 2009) have been reported to be attracted to barley plants exposed to the volatiles emitted by undamaged weeds [Cirsium spp., Chenopodium album L.] or conspecifics (for reviews, see Ahman and Ninkovic 2010; Glinwood 2010; Ninkovic 2010; Glinwood et al. 2011).

Volatile signals being rapidly diluted in the atmosphere, the distance at which VOC-mediated interactions can occur is often short, thus making the leaves closest to the emitter more likely to perceive VOCs. It is very likely that these leaves belong to the emitter or, for plant species with limited dispersal, to genetically related neighbours (Heil and Karban 2010; Heil and AdameÁlvarez 2010). In addition to a role in direct (repulsion of herbivores) and indirect (attraction of insect predators) plant defences, kin selection (i.e., the selection of genetically related plants) has been highlighted as a possible ecological role of VOCs emitted aboveground by plants damaged by herbivores (Heil and Karban 2010; Karban et al. 2011). This hypothesis is supported by experiments showing that sagebrush (Artemisia tridentata Nutt.) plants were less damaged by herbivores when they received volatile cues emitted by genetically identical ramets (Karban and Shiojiri 2009) or by conspecifics belonging to the same chemotype (Karban et al. 2014a). Because VOCs can move from the site of attack faster than long distance signals transported via vascular connections and are able to prime undamaged parts of a plant (Heil and Silva Bueno 2007; Frost et al. 2007; Rodriguez-Saona et al. 2009), they are also particularly well-suited candidates for long distance signalling between different parts of the same plant ('within-plant signalling') and can act synergistically with vascular signals to systemically induce costly defence mechanisms in distal plant organs (Frost et al. 2008a; Heil and Ton 2008; Karban et al. 2011).

\section{Plants can detect root-emitted chemical signals originating from their neighbours}

Plant roots can release molecules in the soil that will negatively affect the germination and/or growth of neighbours (Bertin et al. 2003; Perry et al. 2007). The observation that one plant can influence its neighbours through the emission of secondary metabolites is referred to as 'allelopathy' (allelon=mutual and pathos $=$ suffering or feeling). In 1996, the International Allelopathy Society defined allelopathy as 'any process involving secondary metabolites produced by plants, microorganisms, viruses, and fungi that influence the growth and development of agricultural and biological systems (excluding animals), including positive and negative effects' (Koocheki et al. 2013). This definition has been criticized because of its broad nature covering all chemical interactions that a plant can have with its neighbours. In addition, although 'allelopathy' refers to both the negative and positive effects of one plant on another, many scientists use the term preferentially when describing the negative effects associated with the emission of secondary metabolites (Inderjit and Weiner 2001; Inderjit and Duke 2003; Field et al. 2006). There are many examples of negative plant-plant interactions mediated by root exudates in the scientific literature, particularly in relation to exotic plant invasion (Callaway and Aschehoug 2000; Callaway and Ridenour 2004) and crop-weed interactions in agricultural systems (de Albuquerque et al. 2011), but an exhaustive listing is beyond the scope of this paper (for reviews, see Perry et al. 2007; Koocheki et al. 2013).

Positive intraspecific plant-plant interactions have been demonstrated in Vicia faba L. (Chamberlain et al. 2001; Guerrieri et al. 2002) and Phaseolus lunatus L. (Dicke and Dijkman 2001). Guerrieri et al. (2002) observed that the parasitoid Aphidius ervi Haliday was more attracted to uninfested $V$. faba plants that were potted with plants infested by aphids (Acyrthosiphon pisum [Harris]) or were placed in a hydroponic solution that had previously been used for the growth of infested V. faba plants. Similarly, Dicke and Dijkman (2001) observed that uninfested lima bean plants became more 
attractive to the predatory mite Phytoseiulus persimilis Athias-Henriot when they were incubated in a volume of distilled water that had previously contained the roots of a lima bean plant infested with spider mites (Tetranychus urticae Koch). In split-root experiments, it has been demonstrated that unstressed plants (Pisum sativum L., Cynodon dactylon [L.] Pers., Digitaria sanguinalis [L.] Scop. and Stenotaphrum secundatum [Walter] O. Kuntze) are able to perceive water soluble stress cues released by the roots of their drought-stressed neighbour. In addition, the unstressed receiver plants were able to propagate the signal, causing neighbouring plants to close their stomata, as stressed plants do (Falik et al. 2011, 2012). Recently, it has been reported that root exudates can also influence the flowering timing of neighbours (Falik et al. 2014). Using Brassica rapa L., Falik et al. (2014) showed that plants produced under short-day conditions and treated with soil leachates collected from plants produced under long-day conditions reduce the biomass allocation to vegetative organs and accelerate the flowering process compared with plants produced under short-day conditions and exposed to soil leachates collected from short-day plants.

When growing in the soil, plant roots can detect the presence of neighbours, differentiate self from non-self roots, and sense the degree of genetic relatedness between different root parts (kin recognition) (Callaway 2002; de Kroon 2007; Chen et al. 2012; Faget et al. 2013; Depuydt 2014). Self/non-self recognition has been documented for various plant species including Ambrosia dumosa Payne and Larrea tridentata Cov. (Mahall and Callaway 1991), soybean (Glycine max [L.] Merrill) (Gersani et al. 2001), rice (Oryza sativa L.) (Fang et al. 2013), pea (P. sativum) (Falik et al. 2003), buffalo grass (Buchloe dactyloides) (Gruntman and Novoplansky 2004), hevea (Hevea brasiliensis Müll. Arg), corn (Zea mays L.) (Gonkhamdee et al. 2010) and Hieracium pilosella L. (Schmid et al. 2015). Depending on the plant species, at least two kinds of root behaviour have been observed when two plant individuals share the same volume of soil: (1) avoidance of self competition and enhanced root development in response to competition with a non-self neighbour (Gersani et al. 2001; Falik et al. 2003; Gruntman and Novoplansky 2004) or (2) segregation and avoidance of roots belonging to competitors (Mahall and Callaway 1991; Fang et al. 2013; Schmid et al. 2015). Various mechanisms that might explain how plants identify their neighbours have been proposed in the literature (Chen et al. 2012; Depuydt 2014). Because the physiological integrity of plants seems to be necessary to discriminate self from non-self roots, it has been suggested that internal oscillations of hormone levels and/or electrical signals could be the primary mechanism used by plants to recognize roots as self (Falik et al. 2003; Gruntman and Novoplansky 2004). A role for rootemitted chemical signals in self/non-self recognition and kin recognition has also been suggested (Chen et al. 2012; Fang et al. 2013). Both laboratory and greenhouse experiments have shown that root exudates can carry information about the degree of genetic relatedness, allowing plants exposed to these compounds to distinguish kin and non-kin individuals. In Arabidopsis thaliana (L.) Heynh, the root system of plants exposed to the root exudates of unrelated seedlings was characterized by a greater number of lateral roots than the plants exposed to their own exudates or to the exudates of siblings (Biedrzycki et al. 2010). In a greenhouse experiment designed to mimic soil natural conditions (composition, microbial activity and exudate concentration), Semchenko et al. (2014) found that root exudates can also carry information about the species identity and population origin of neighbours. In their experiment, Deschampsia caespitosa (L.) plants showed an increase in specific root length and lateral root branching following the application of root exudates produced by unrelated conspecifics coming from the same population. Such alteration of root system architectural traits was suppressed in plants exposed to the chemicals released by sibling roots. Interestingly, root growth stimulation was not observed when $D$. caespitosa plants received chemicals secreted by the roots of a different plant species (Lychnis flos-cuculi L.), indicating that recipient plants can use information carried by root exudates to differentiate kin from non-kin neighbours and recognise individuals living in the same population (Semchenko et al. 2014).

Taken together, these results show that root exudates play significant roles in plant-plant interactions and can affect receiver plants both aboveground (herbivore resistance, stomatal aperture, flowering timing) and belowground (allelopathy, kin recognition).

\section{Plant roots release VOCs involved in belowground biotic interactions}

The release of VOCs by plant roots has been suggested for both monocotyledonous and dicotyledonous plant 
species submitted to biotic (insect herbivore, phytopathogenic fungi and bacteria) and/or abiotic stresses (mechanical damage and water/drought stress) (Table 1). Depending on the plant species studied, volatile blends released belowground by plant roots can be characterized by compounds belonging to various chemical families, particularly terpenoids (Rasmann et al. 2005; Lin et al. 2007; Ali et al. 2010), fatty acid derivatives (Gfeller et al. 2013) or sulphur-containing compounds (Ferry et al. 2007; Crespo et al. 2012; Danner et al. 2015). Important ecological roles have been associated with root-emitted VOCs (Fig. 1). Briefly, they have been shown to mediate interactions between plants and phytophagous pests such as insect herbivores (Sutherland and Hillier 1974; Guerin and Ryan 1984; Palma et al. 2012; Weissteiner et al. 2012; Robert et al. 2012a) and plant parasitic nematodes (Ali et al. 2011; Farnier et al. 2012). Volatile cues released by roots damaged by insect herbivores are also implicated in belowground plant indirect defences because they attract organisms of the third trophic level, such as insect predators (Neveu et al. 2002; Ferry et al. 2007) and entomopathogenic nematodes (van Tol et al. 2001; Boff et al. 2002; Rasmann et al. 2005; Ali et al. 2011). In addition to the review articles published so far and focusing on belowground VOCs (Wenke et al. 2010; Rasmann et al. 2012; Peñuelas et al. 2014), Table 1 presents a chronological literature review of the studies on root VOC production and VOC-mediated interactions between plant roots and soil organisms. This review gives the plant model(s) used in experiments, the (a)biotic stresses experienced by plants, the questions raised, the type of biological sample and the analytical techniques used to trap and analyse VOCs produced by plant roots. It shows that more than half the studies published so far focus on root VOC production by three major plant models: Z. mays, Citrus spp. and Brassica spp.

When submitted to Diabrotica virgifera virgifera LeConte feeding, maize roots systemically produce a specific VOC blend dominated by $(E)$ - $\beta$-caryophyllene (Rasmann et al. 2005; Hiltpold et al. 2011), a sesquiterpene produced from farnesyl diphosphate via the maize terpene synthase 23 (TPS23) (Köllner et al. 2008) and possessing remarkable diffusion properties in sand and soil (Hiltpold and Turlings 2008). When released by insect-damaged maize roots, $(E)$ - $\beta$-caryophyllene was identified as the main belowground chemical attractant for entomopathogenic nematodes (Heterorhabditis megidis Poinar, Jackson \& Klein and Heterorhabditis bacteriophora Poinar) in laboratory and field experiments (Rasmann et al. 2005; Rasmann and Turlings 2007, 2008; Hiltpold et al. 2010a). The discovery that a root-emitted signal produced by plants infested by $D$. virgifera virgifera larvae is able to recruit organisms of the third trophic level as an indirect plant defence mechanism led to the development of new crop protection strategies using entomopathogenic nematodes as biological control agents to reduce $D$. virgifera virgifera emergence and root damage in the field (Hiltpold et al. 2010c; Hiltpold and Turlings 2012). Several attempts to improve the searching efficiency of entomopathogenic nematodes were made, notably by selecting an entomopathogenic nematode strain for enhanced responsiveness to (E)- $\beta$-caryophyllene (Hiltpold et al. 2010a, b) or by genetically engineering a maize variety that had lost the ability to produce $(E)$ - $\beta$-caryophyllene in order to restore the release of the sesquiterpene signal (Degenhardt et al. 2009). Although both pest management strategies led to a decrease in $D$. virgifera virgifera adult emergence in the field (Degenhardt et al. 2009; Hiltpold et al. 2010a), there were physiological and ecological costs involved in the use of the selected entomopathogenic nematode strain (small decrease in infectiousness) (Hiltpold et al. 2010a), and the genetically engineered maize plants (decrease in seed germination, plant growth and yield, and increased attractiveness to adults and larvae of an aboveground plant pest) (Robert et al. 2013a). When searching for a suitable host, D. virgifera virgifera larvae also use $(E)-\beta$ caryophyllene as a volatile attractant in a plant background odour to locate plants with increased susceptibility infested by conspecifics and aggregate in a density-dependent manner (Robert et al. 2012a, b).

As for root herbivory, maize leaf infestation by an insect herbivore also induces changes in VOC emissions by plant roots (Rasmann and Turlings 2007; Robert et al. 2012a). Root VOC analyses showed that the (E)- $\beta$ caryophyllene production of plants infested simultaneously by a leaf (Spodoptera littoralis Boisduval) and a root (D. virgifera virgifera) herbivore is significantly lower than that of plants infested by $D$. virgifera virgifera larvae only. This decrease in $(E)-\beta$ caryophyllene production by maize roots correlated with a reduction in the attraction of double infested plants for H. megidis (Rasmann and Turlings 2007). In addition, when performing behavioural assays, Robert et al. (2012a) showed that D. virgifera virgifera larvae were significantly more attracted by the roots of healthy 


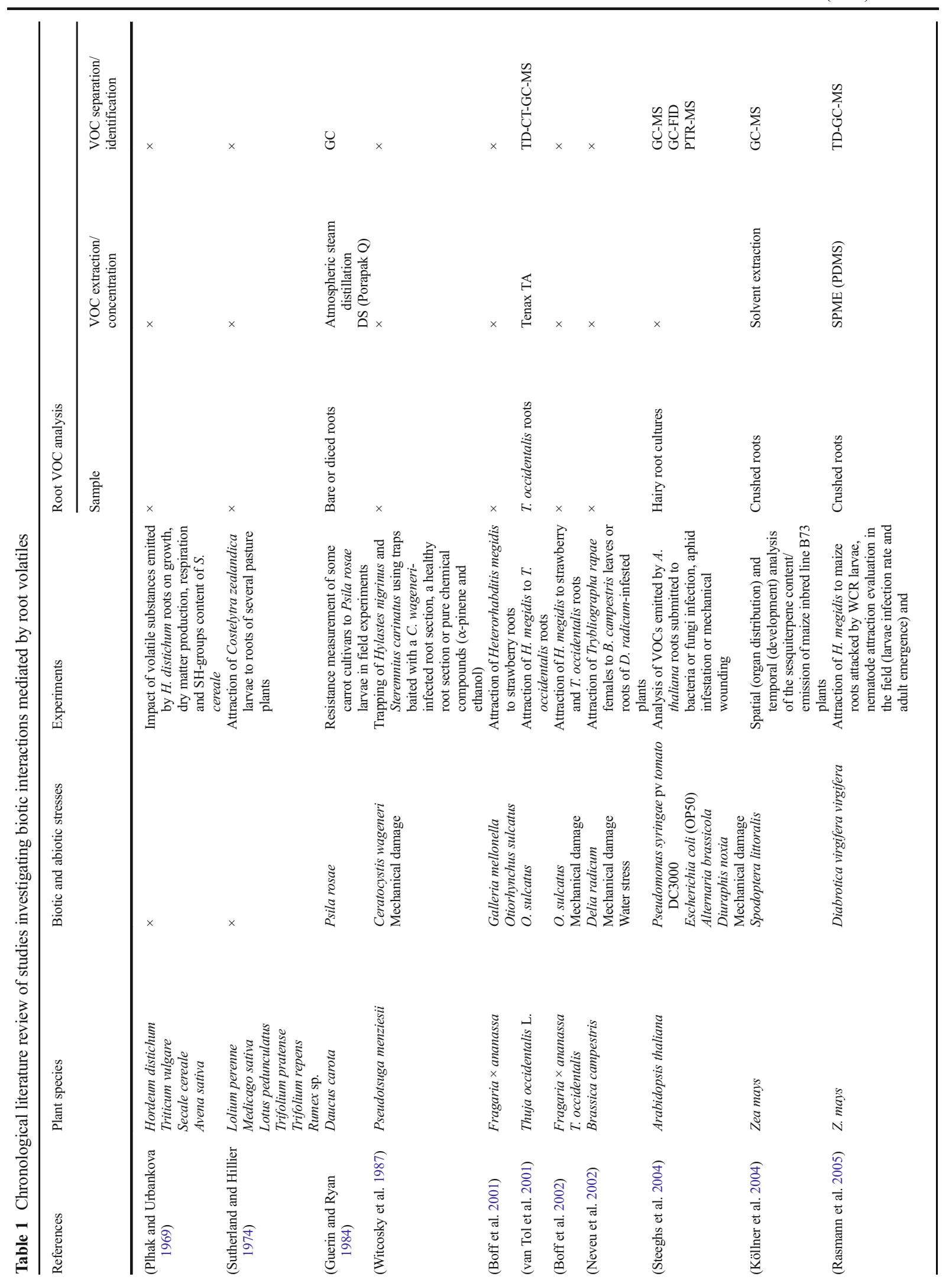




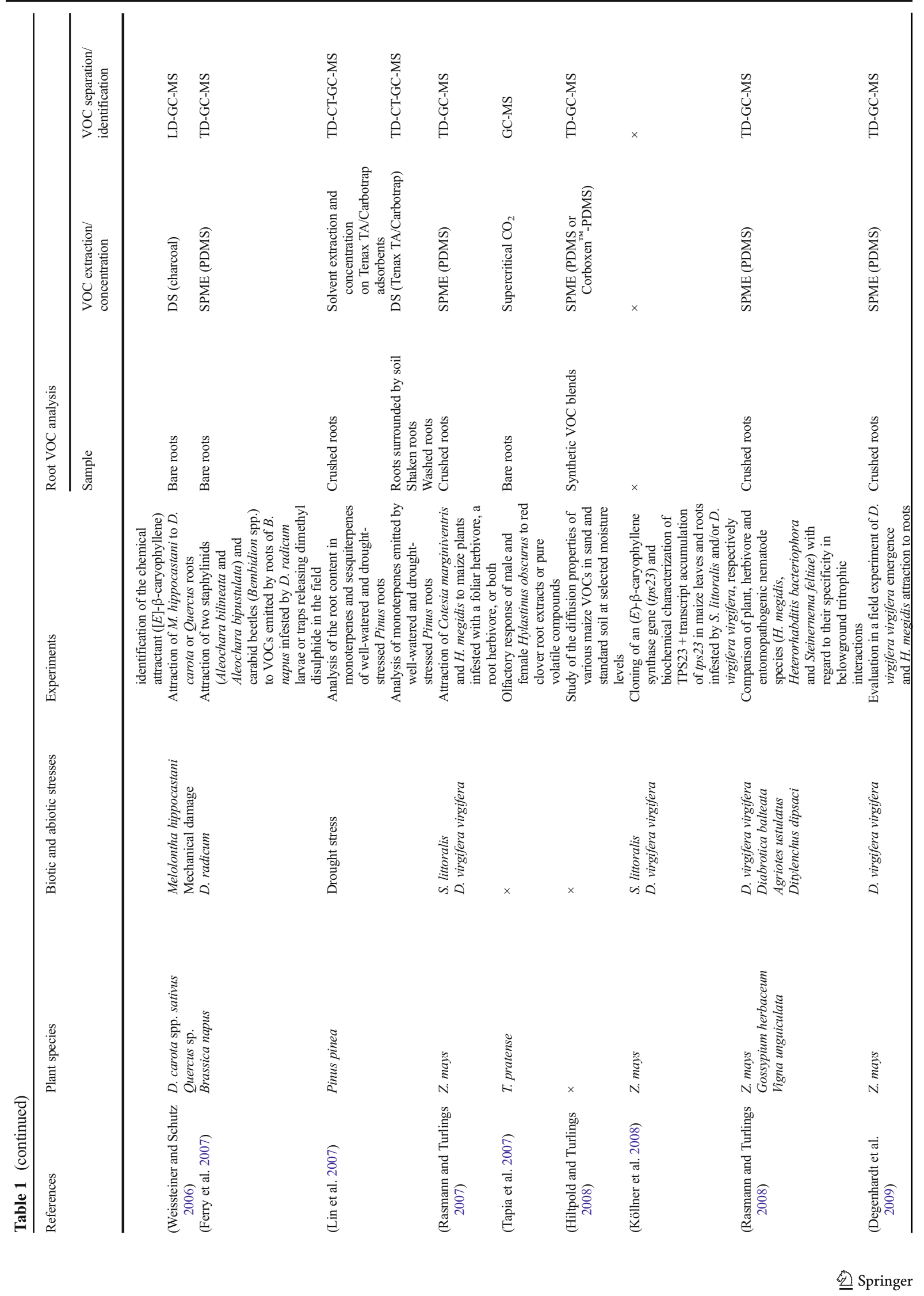




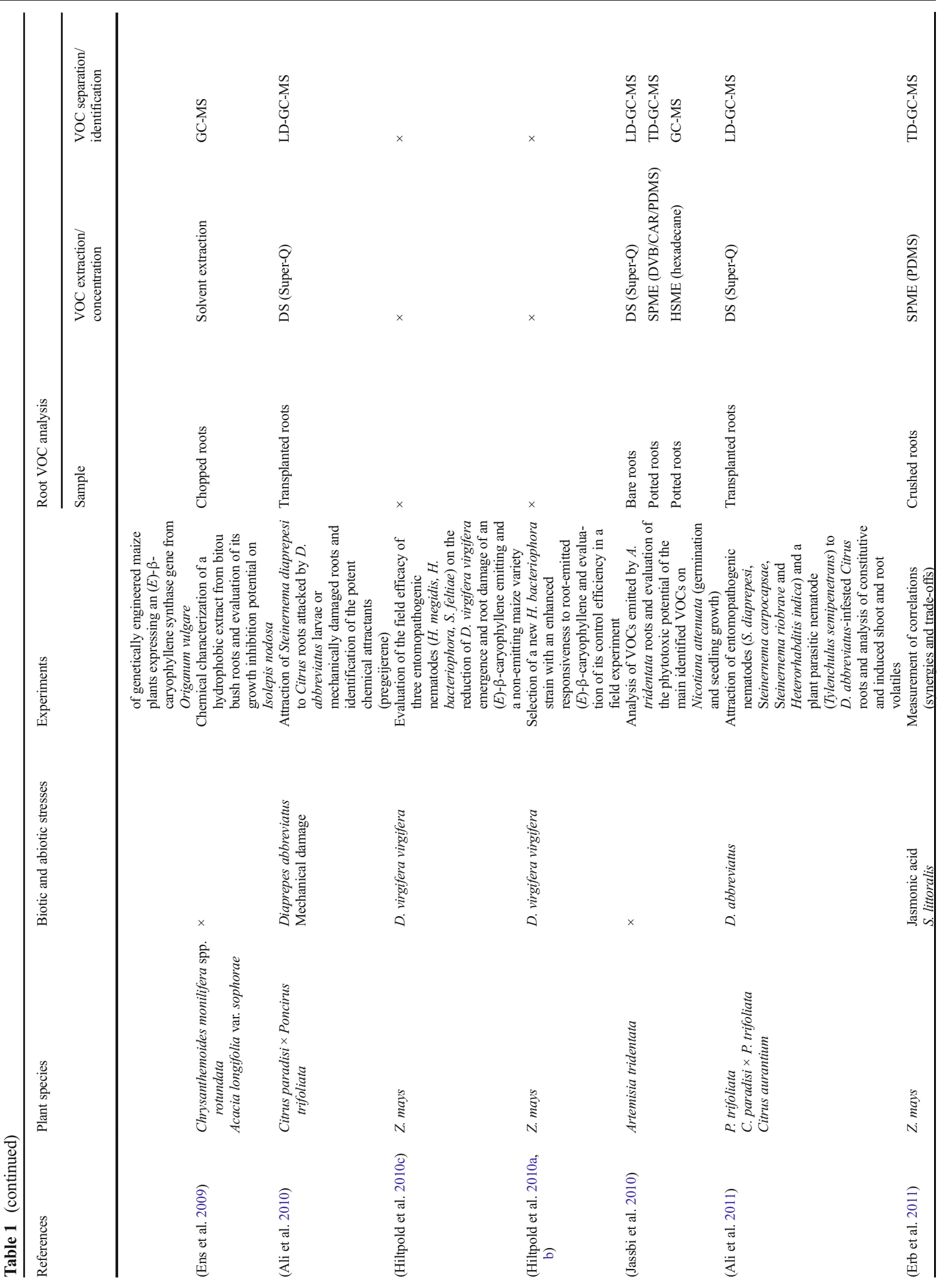




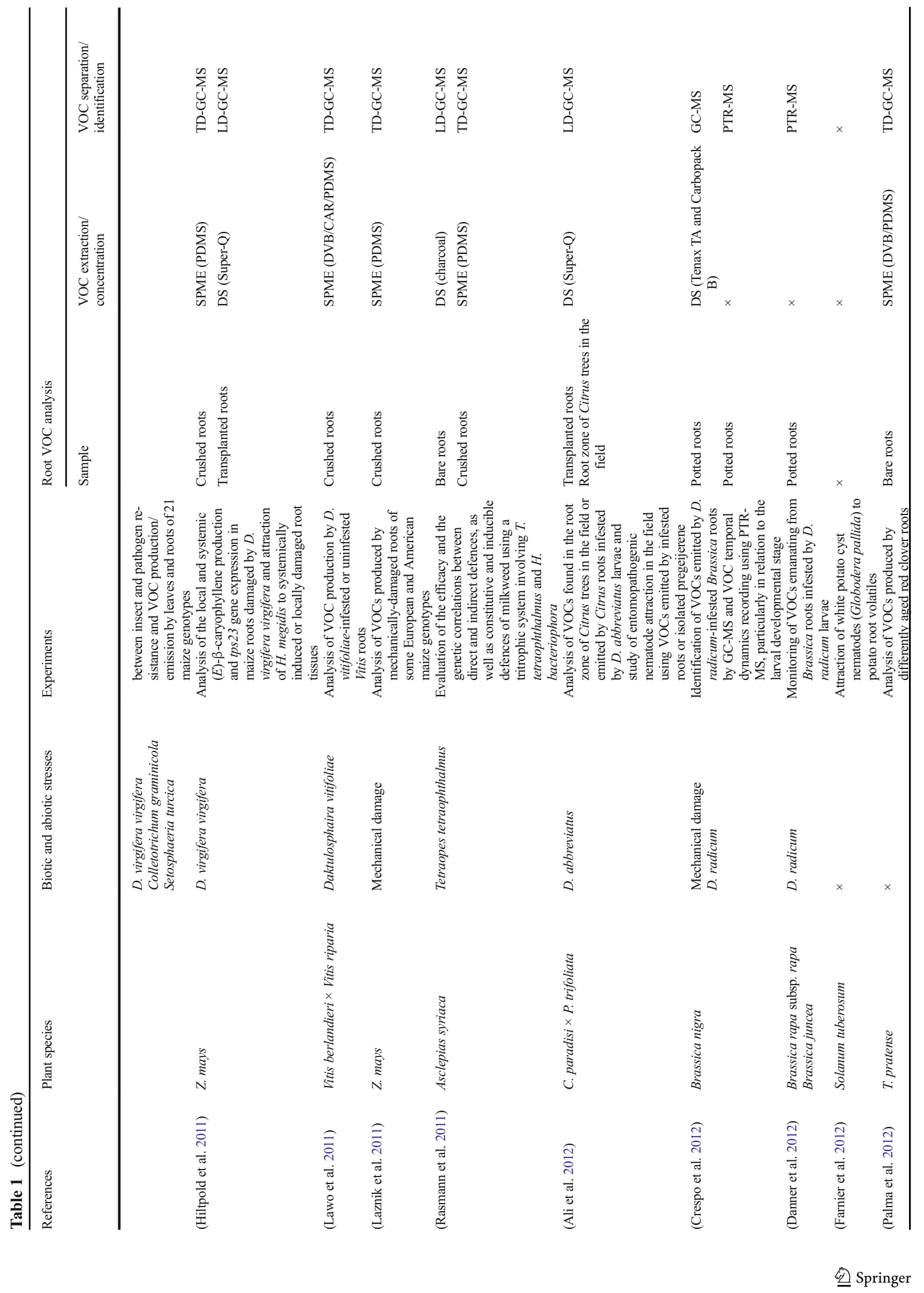




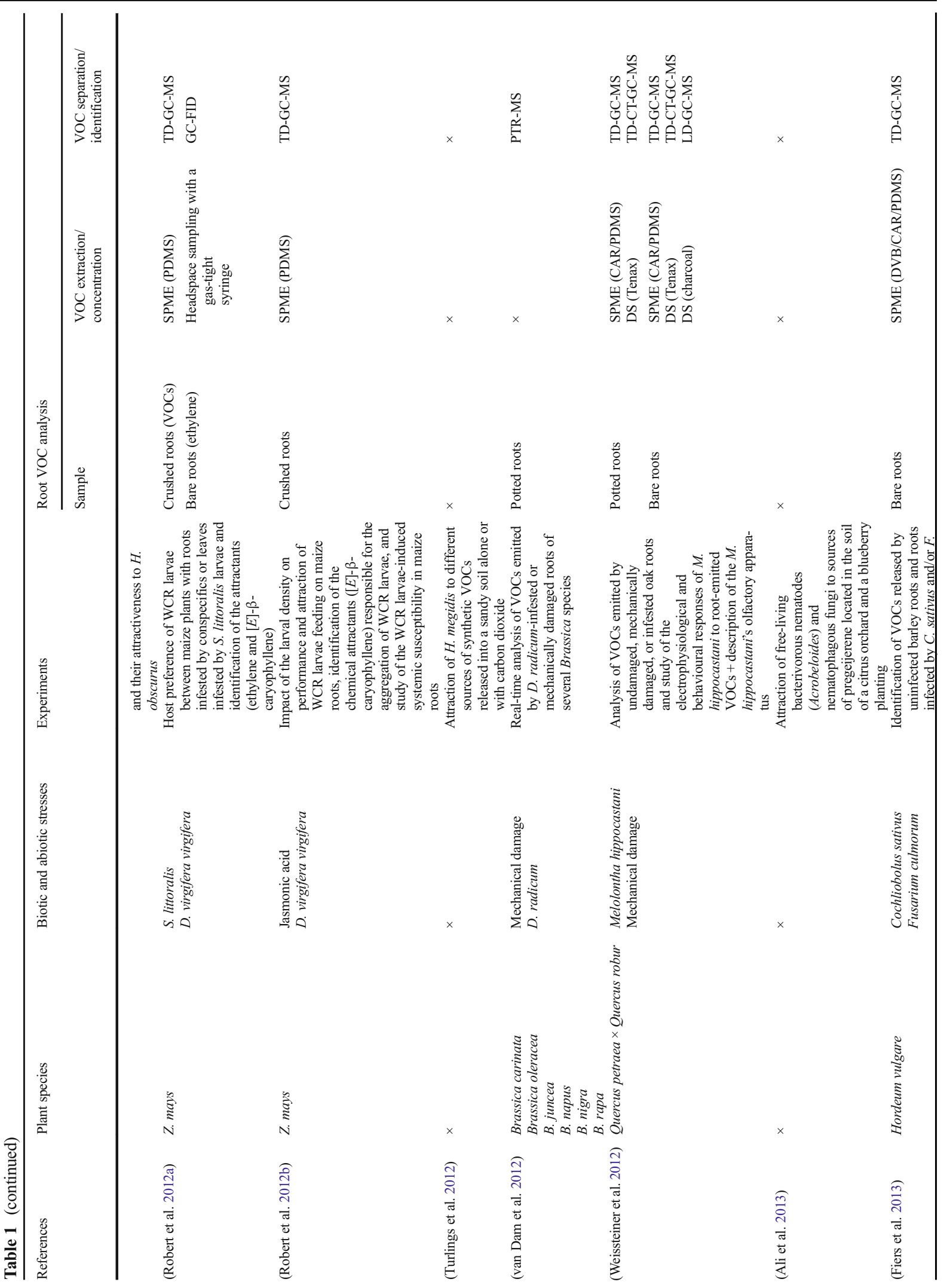




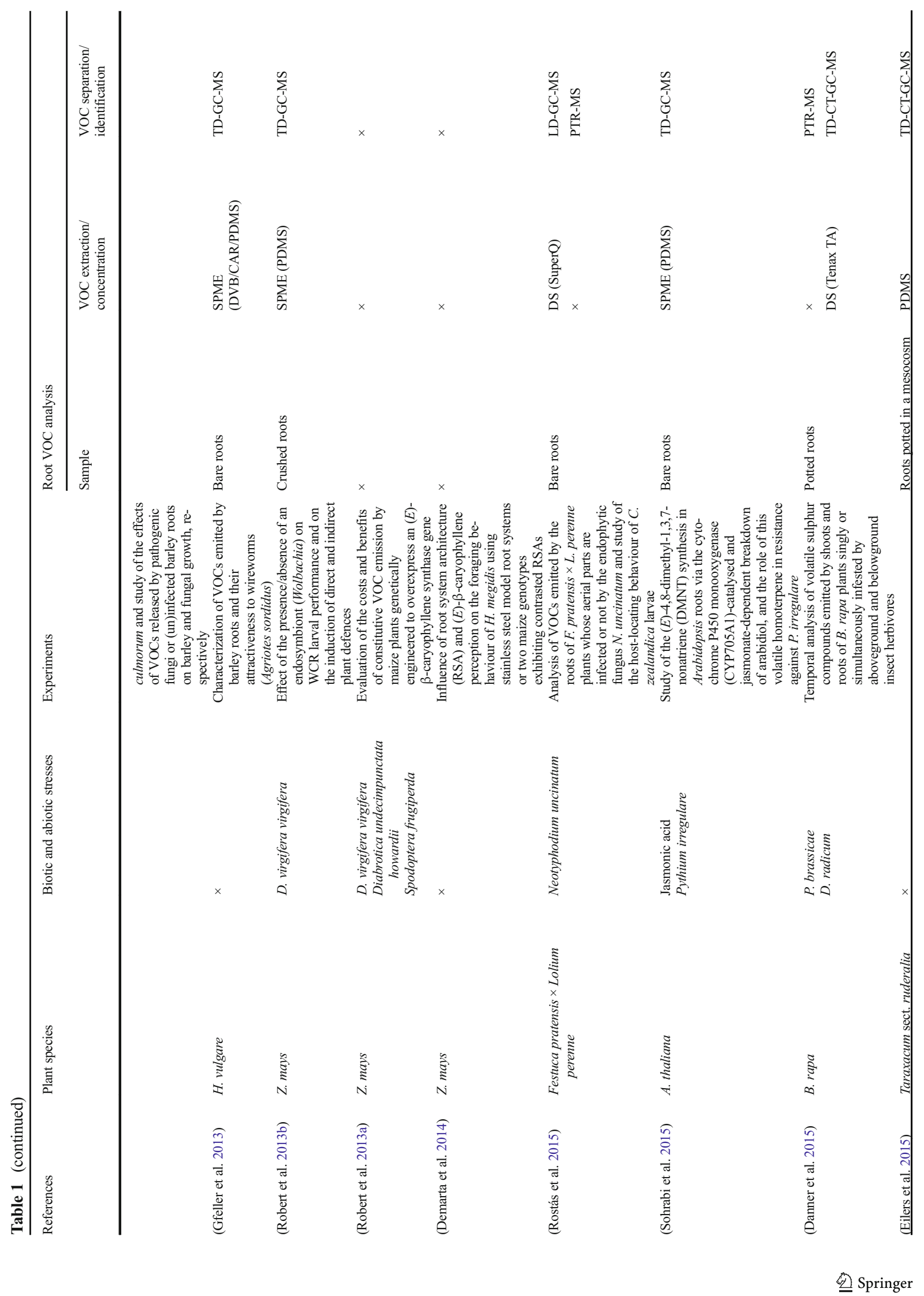




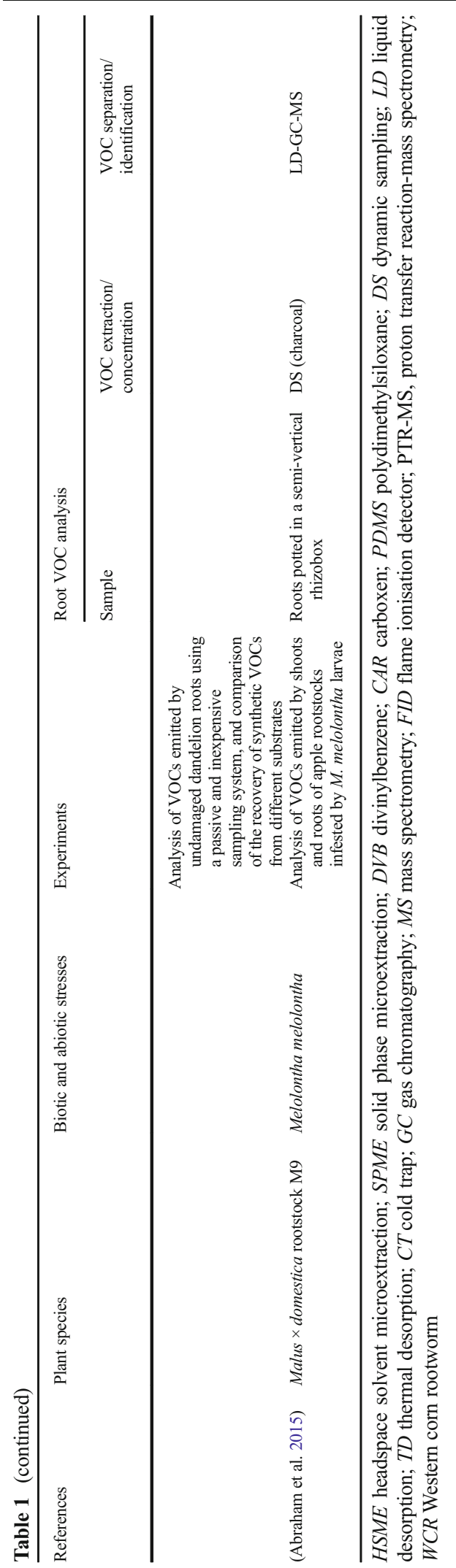


plants than those of plants infested by S. littoralis. Although solid phase microextraction and gas chromatography-mass spectrometry (SPME-GC-MS) analyses did not show any differences between VOCs produced by the roots of healthy and infested plants, complementary analyses focusing on ethylene emission showed that roots of $S$. littoralis-infested plants released significantly less ethylene than those of healthy plants. These results led to the hypothesis that, in addition to $(E)-\beta$ caryophyllene, $D$. virgifera virgifera larvae are also able to use ethylene emission as a general cue to detect healthy plants in the host selection process (Robert et al. 2012a).

Tritrophic interactions between plant roots, a phytophagous insect and soil nematodes were also studied using the rootstock Citrus paradisi Macf. $\times$ Poncirus trifoliata L. Raf. ('Swingle citrumelo'), the larvae of the root weevil (Diaprepes abbreviatus [L.]), and entomopathogenic (Steinernema diaprepesi Nguyen \& Duncan, Steinernema carpocapsae, Steinernema riobrave and Heterorhabditis indica) and plant parasitic (Tylenchulus semipenetrans) nematodes (Ali et al. 2010, 2011). Using in situ dynamic sampling systems to trap and concentrate VOCs emitted by roots before GC-MS analyses, the $\mathrm{C}_{12}$ terpene pregeijerene (1,5-dimethylcyclodeca1,5,7-triene) was identified as the main VOC released by the roots of the Swingle citrumelo rootstock infested by D. abbreviatus larvae (Ali et al. 2010, 2011), as well as the main VOC found in the root zone of Citrus trees in an unmanaged orchard (Ali et al. 2012). Depending on the plant species studied, pregeijerene can be produced by roots constitutively, as in the Swingle citrumelo's parent line $P$. trifoliata, or only in response to insect feeding. The volatile blend emitted by $D$. abbreviatus-infested roots was shown to attract entomopathogenic nematodes both in olfactometer assays (Ali et al. 2010, 2011) and in field experiments (Ali et al. 2012). Among all the VOCs emitted by insect-damaged Citrus roots, it has been demonstrated that isolated pregeijerene was enough to attract naturally occurring entomopathogenic nematodes, as well as free-living bacterivorous nematodes (Acrobeloides), and to increase the mortality rate of insect larvae in the field (Ali et al. 2012, 2013). Given that VOCs emitted by Citrus roots infested by D. abbreviatus appeared to attract plant parasitic nematodes, the use of a rootemitted cue to attract entomopathogenic nematodes as an indirect plant defence strategy could have ecological costs for the plant emitter (Ali et al. 2011). As suggested by Ali et al. (2011), these costs could be reduced in plant lines susceptible to plant parasitic nematodes by using volatile cues that would be released only after herbivore attack. As observed in SPME-GC-MS analyses of maize roots (Robert et al. 2012a), aboveground herbivory on the Swingle citrumelo rootstock by $D$. abbreviatus did not seem to induce the production of root VOCs that differed from that produced by healthy plants (Ali et al. 2011).

VOCs emitted by Brassica roots infested by cabbage root fly larvae (Delia radicum L.) were also shown to be attractive for insects of the third trophic level, such as females of the parasitoid species Trybliographa rapae Westwood, rove beetles (Aleochara bilineata and Aleochara bipustulata), and carabid beetles in the genus Bembidion (Neveu et al. 2002; Ferry et al. 2007). GCMS and proton transfer reaction-mass spectrometry (PTR-MS) analyses have shown that insect-damaged Brassica roots release mainly highly volatile sulphur compounds (methanethiol, dimethyl sulphide, dimethyl disulphide and dimethyl trisulphide) and glucosinolate breakdown products (thiocyanates and isothiocyanates) in the soil, with a VOC emission pattern depending on the plant species studied (van Dam et al. 2012; Danner et al. 2012; Crespo et al. 2012; Danner et al. 2015). To date, PTR-MS analyses of root-emitted VOCs have been performed only on potted Brassica spp. root systems (Crespo et al. 2012) and on hairy root cultures of $A$. thaliana submitted to bacteria or fungi infection, aphid infestation or mechanical wounding (Steeghs et al. 2004).

Aboveground, VOCs emitted by damaged plant parts can prime or induce direct/indirect defence mechanisms in yet undamaged parts of the same plant (Das et al. 2013). Both VOCs emitted at the site of attack and chemical signals (e.g., plant hormones) travelling inside the vascular tissues of the attacked plant mediate interactions between damaged and undamaged plant parts (Erb et al. 2008; Das et al. 2013). Given that the roots of plants attacked by insect herbivores also synthesise and release VOCs in the soil (Table 1), their roles in mediating interactions between the roots and shoots of the same plant are worth investigating (Fig. 2). Whether or not root-emitted VOCs diffusing from the rhizosphere into the phyllosphere can mediate root-shoot interactions is still poorly documented, but this within-plant signalling mechanism has been hypothesized as a possible way for plants to coordinate aboveground and belowground defences (Erb et al. 2008). 


\section{Studying VOC-mediated root-root interactions: challenges and opportunities}

Given that (1) VOCs play important ecological roles in plant-plant interactions aboveground, (2) plants can detect chemical signals emitted in the rhizosphere of their neighbours (roots and associated microorganisms), and (3) roots are able to synthesise and release VOCs in the soil (Table 1), questions arise relating to the ecological roles played by belowground VOCs in root-root interactions (Schenkel et al. 2015). With regard to allelopathic interactions, plant VOCs are able to generate oxidative stress (Zunino and Zygadlo 2004; Singh et al. 2006). In addition, they can affect germination, root and shoot growth (Bradow and Connick 1990; Fischer et al. 1994; Kong et al. 2002; Singh et al. 2002; Barney et al. 2005), mitosis and cell size (Romagni et al. 2000; Nishida et al. 2005), chlorophyll content and fluorescence (Romagni et al. 2000; Kong et al. 2002; Singh et al. 2002), mitochondrial respiration (Abrahim et al. 2000, 2003; Singh et al. 2005), DNA synthesis (Nishida et al. 2005), and gene expression in exposed plants (Horiuchi et al. 2007). Compared with VOC-mediated plant-plant interaction studies performed aboveground, the amount of published research on the roles played by root VOCs in plant-plant interactions is much lower. For example, using an in vitro experimental set-up, it has been documented that some volatile terpenoids emitted by the bitou bush (Chrysanthemoides monilifera spp. rotundata [DC.] T. Norl.) (Ens et al. 2009) and sagebrush roots (Jassbi et al. 2010) in the soil can be phytotoxic to Isolepis nodosa (Rott.) R. Br. and Nicotiana attenuata Torr., respectively. In addition, sesquiterpenoids released by roots (e.g., sesquiterpene lactones) can also act as germination stimulants for parasitic plants (Striga and Orobranche spp.) (Bouwmeester et al. 2003; Rasmann et al. 2012). With regard to volatile phytohormones, ethylene was reported to be constitutively emitted by maize root systems (Robert et al. 2012a). Although ethylene can act as a non-specific volatile signal aboveground (Pierik et al. 2003), a role of this VOC in mediating root-root interactions is still unknown. In the next section, we will discuss the environmental fate of VOCs emitted by plant roots and, given the belowground location of root systems, we will look at some of the technical challenges in the design of experimental devices for (1) analysing the VOCs released by plant roots and (2) studying the ecological roles played by root-emitted VOCs in plant-plant interactions.
Environmental fate of root-emitted VOCs

The distance at which volatile cues can act as interplant signals is an important issue when studying their ecological roles, particularly when moving from controlled laboratory assays to field experiments. Aboveground, VOC-mediated plant-plant interactions are reported to occur over distances that vary depending on the plant species and environmental parameters (such as atmospheric ozone concentration) (Blande et al. 2010). In field experiments involving sagebrush and tobacco, plant-plant signalling was demonstrated to occur over distances ranging from $10 \mathrm{~cm}$ (sagebrush to tobacco) to $60 \mathrm{~cm}$ (sagebrush to sagebrush) (Karban et al. 2003, 2006). Similarly, the secretion of extra floral nectar by lima bean leaves was reported to occur in receiver plants located up to $50 \mathrm{~cm}$ away from the emitter (Heil and Adame-Álvarez 2010). Given that a volatile compound must be perceived at a physiologically active concentration by a neighbouring plant before it can be considered as a signal mediating plant-plant interactions (Firn and Jones 1995; Preston et al. 2001), the environmental fate of root-emitted VOCs in the soil is of crucial importance and will be linked to their chemical stability, their production rate by plant roots, and their interactions with the solid, liquid and gaseous components of the soil ecosystem (Perry et al. 2007; Zeng 2014). For instance, they can be diluted in the gaseous phase of the soil matrix, solubilized into the soil solution (particularly polar oxygenated VOCs) (Fischer et al. 1994; Hiltpold and Turlings 2008; Peñuelas et al. 2014), used as a carbon source by soil microorganisms (Misra et al. 1996; Cleveland and Yavitt 1998; Kleinheinz et al. 1999; Owen et al. 2007; Ramirez et al. 2009), adsorbed into soil particle surfaces (Inderjit and Dakshini 1995; Ruiz et al. 1998) or subjected to physico-chemical degradation (Perry et al. 2007). Taken together, these phenomena lead to a decrease in VOC concentration with increasing distance from the source. The distance that a volatile signal can travel will depend on its physicochemical properties (particularly polarity) and its ability to interact with the soil environment (Fischer et al. 1994; Ruiz et al. 1998). For example, it has been shown that volatile sesquiterpenes ([E]- $\beta$-caryophyllene, $[E]-\beta$ farnesene) have better diffusion capacities in sand and soil than green leaf volatiles ([E]-hex-2-enal and $[Z]$ hex-3-en-1-ol) and that both soil moisture level and soil composition affect the distance travelled by volatile signals (Hiltpold and Turlings 2008). In addition, 
oxygenated monoterpenes have greater water solubilities than monoterpene hydrocarbons with a similar skeleton and are thus more likely to be solubilized into the soil solution (Fischer et al. 1994). More research efforts are needed to determine the distances over which VOCs emitted by undisturbed root systems can travel in the soil environment (either solubilized into the soil solution or diffusing in the soil gaseous phase).

Technical challenges and perspectives

Due to their belowground location, studying root-root interactions mediated by VOCs is challenging and requires innovative tools in order to (1) identify the volatile signals released into the plant rhizosphere (Rasmann et al. 2012; Campos-Herrera et al. 2013; Hiltpold et al. 2013), (2) follow the temporal variations in VOC emission (composition of the VOC blends and individual VOC concentrations) (Danner et al. 2012) and (3) conduct bioassays on the roles played by root-emitted VOCs in plant-plant interactions.

As in the case of VOCs that are synthesised and released by aboveground plant tissues (Tholl et al. 2006), VOCs produced by belowground plant organs have been analysed mainly using GC-MS and PTR-MS (Table 1). A major drawback with GC-MS is that VOCs need to be sampled and concentrated before being injected into the injection port of a gas chromatograph. Belowground VOCs can be collected using static sampling methods such as SPME or solvent microextraction (HSME). These methods concentrate VOCs located in the headspace of a sample either in a small volume of solvent (for HSME) or on a fused silica fibre coated with ab/adsorbent materials (for SPME) (Tholl et al. 2006; Jassbi et al. 2010). Depending on the physico-chemical properties of the solvent used in HSME or on the characteristics of both the liquid phase (polarity and film thickness) and porous particles (specific surface area, pore sizes and distribution) used to coat the SPME fibres, the selectivity of the sampling method can be adjusted for VOCs of known polarity and volatility (Shirey 1999; Tholl et al. 2006). Both SPME and HSME have been successfully applied to crushed root tissues (Rasmann et al. 2005; Hiltpold et al. 2011; Laznik et al. 2011; Erb et al. 2011; Lawo et al. 2011; Robert et al. 2012a), isolated root parts (Palma et al. 2012; Weissteiner et al. 2012; Fiers et al. 2013; Gfeller et al. 2013) and unexcavated root systems (Jassbi et al. 2010; Weissteiner et al. 2012). In addition to these techniques, passive sampling approaches involving the use of polydimethylsiloxane (PDMS) sorbents were successfully used to collect non-polar compounds (thiophenes) that are constitutively released by Tagetes roots (Mohney et al. 2009), and VOCs that are emitted by Taraxacum sect. ruderalia roots growing in a mesocosm (Eilers et al. 2015). Compared with dynamic sampling devices, these static sampling methods are easier to set up and allow the rapid identification of VOCs produced by root tissues that were extracted or not from the soil. In situ soil VOC collection on packed adsorbents using dynamic sampling methods have also been used with root systems that were initially transplanted in an autoclaved sandy soil (Ali et al. 2010, 2011; Hiltpold et al. 2011) or with roots growing in a semi-vertical rhizotron (Abraham et al. 2015). In comparison with static sampling methods, the use of a purified airflow to trap VOCs located in the soil porosity allows the emission rate of VOCs emitted by plant roots to be measured in situ (Rasmann et al. 2012; Hiltpold et al. 2013), but it has the disadvantage of modifying the composition of the soil atmosphere if ambient air is used for the sampling of VOCs. Several packed carbon-based adsorbents or organic polymers are commercially available for the concentration of VOCs using a dynamic sampling device. As these materials do not have the same selectivity for VOCs, it is often necessary to combine different matrices (e.g., in multi-bed tubes) in order to trap VOCs of different polarity and volatility (Tholl et al. 2006). Whatever the sampling method used for VOC trapping, the extraction of roots from the soil prior to VOC collection can induce the release of VOCs by roots that had been mechanically damaged during the excavation process. As these molecules would not have been emitted by undisturbed root systems, experimental devices enabling VOCs to be sampled without extracting the roots from the soil are therefore needed for a better characterisation of root-emitted VOCs (Inderjit and Dakshini 1995; Jassbi et al. 2010; Abraham et al. 2015).

Once they have separated by GC, VOCs can then be detected by MS and tentatively identified by comparing their mass spectra with those stored in mass spectral databases. These identifications can then be confirmed by comparing calculated retention indices and MS data with those of authentic standards injected under the same chromatographic conditions. The significant volatile background associated with the soil ecosystem, however, complicates the identification and quantification of VOCs emitted at low concentrations in the soil 
Fig. 3 Diagram of experimental devices designed to study plantplant interactions mediated by root VOCs. (a) Active/dynamic exposure system. A pump (1) pushes clean air into a glass bottle (4a) filled with soil and containing the growing roots of a plant species A (5, emitter plants). The incoming air is filtered on a cartridge filled with activated charcoal (3). The air containing VOCs emitted by the roots of the plant species A is sent to the bottom of a PTFE container (8) filled with soil and containing the growing roots of a plant species A (intraspecific interaction) or B (interspecific interaction) $(9$, recipient plant). A PTFE/glass airflow meter (7) and a flow divider (2) are used to measure and control the airflow rate of the system, respectively. All connections are made via PTFE/glass tubing (6). (b) Passive/static exposure systems. VOCs emitted by the roots of a plant species A (4a) or by slow-release dispensers (4b) in a glass bottle move passively to the bottom of a PTFE container (8) filled with soil and containing the growing roots of a plant species A (intraspecific interaction) or B (interspecific interaction) ( 9 , recipient plant). The emitter compartments are sealed with a nonporous synthetic rubber paste in order to prevent air leakage.

(Drawing: Ir Carolina Levicek)
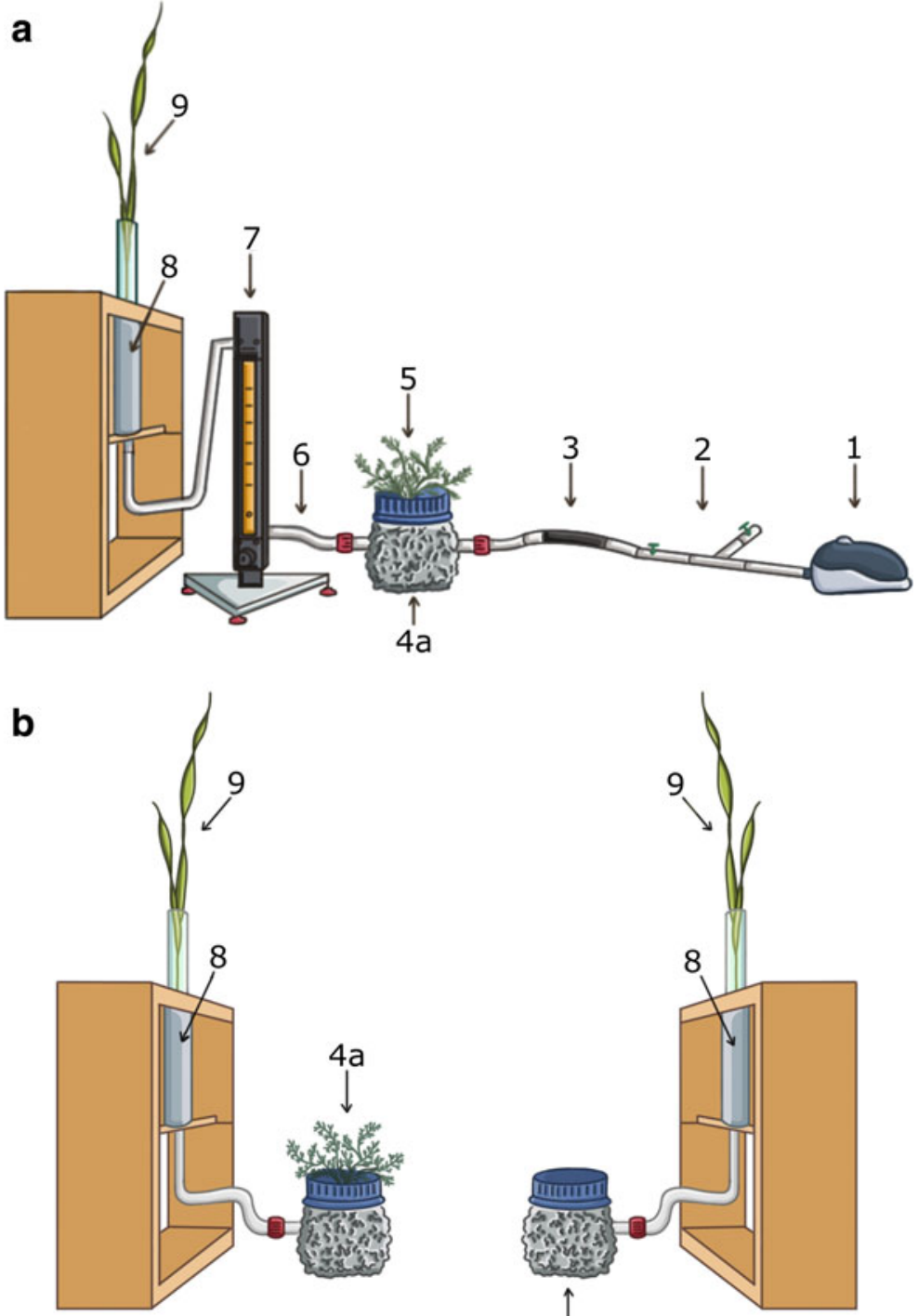

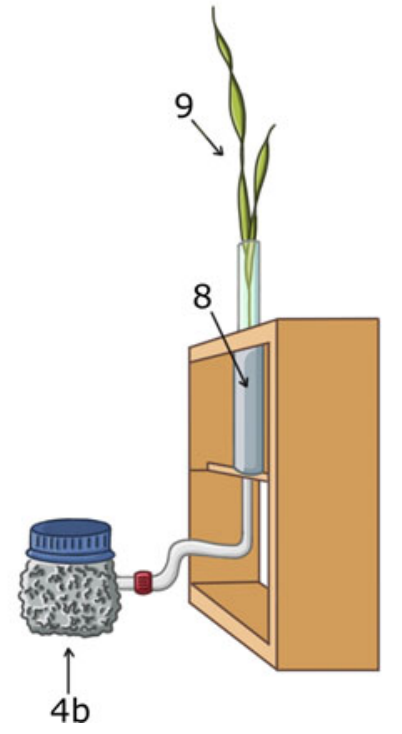

atmosphere because both VOCs released by the roots and the soil environment (including microbial VOCs) are trapped during the sampling of VOCs and injected into the chromatographic column. In order to facilitate the quantification of VOCs emitted by unexcavated root systems, the use of a mass spectrometer synchronously in SCAN (VOC identification) and Selected Ion(s) Monitoring (SIM, VOC quantification) modes can help to overcome this problem. In SIM mode, only the $\mathrm{m} / \mathrm{z}$ ratios possessing a high specificity for the target rootemitted VOCs and a low specificity for the volatile background (the 'noise' of a chromatogram) will be filtered by the mass spectrometer. The full mass spectra obtained in SCAN mode will be used to identify the target VOCs following the procedure described earlier.

PTR-MS has been shown to be an efficient tool for the real-time analysis of root-emitted VOCs in situ (van Dam et al. 2012; Danner et al. 2012; Crespo et al. 2012; Danner et al. 2015). The identity of the molecules entering the ionization chamber, however, cannot be determined using the mass spectral data acquired with this technique because only the mass of a small number of product ions (particularly cluster ions) can be obtained (Campos-Herrera et al. 2013). Combining GC-MS and PTR-MS analyses offers a promising tool for the study of VOCs emitted by roots in their rhizosphere by 
exploiting the advantages of both analytical techniques. Whereas GC-MS enables biogenic VOCs to be rapidly identified by comparing their recorded mass spectra with those contained in mass spectral databases, PTRMS enables the temporal dynamics of root-emitted VOCs to be monitored with a high time resolution, particularly for highly volatile and low molecular weight molecules that are not easily trapped using packed adsorbents prior to GC-MS analyses (Danner et al. 2012; Crespo et al. 2012).

Aboveground, the roles played by volatile cues in interplant signalling have been investigated using various types of experimental devices, including sealed (Farmer and Ryan 1990; Arimura et al. 2000a; Engelberth et al. 2004) or open-flow chambers (Shulaev et al. 1997; Ninkovic 2003; Ton et al. 2006) containing detached leaves/branches or intact plants, and most of these experimental set-ups have been criticized for their lack of ecological relevance (Baldwin et al. 2006; Paschold et al. 2006). In addition to these assays performed under laboratory conditions, field experiments (Karban et al. 2000; Dolch and Tscharntke 2000; Heil and Silva Bueno 2007) and bioassays using transgenic plants unable to release ('mute emitters') or perceive ('deaf receivers') the key volatile signals (Baldwin et al. 2006; Paschold et al. 2006; Inderjit et al. 2009) have demonstrated that VOCs can act as interplant signals in nature. Belowground, original experimental devices have been designed to study the roles played by root-emitted VOCs in biotic interactions. For example, sand-filled olfactometers have been successfully used to test the attractiveness of root volatiles for entomopathogenic nematodes (Rasmann et al. 2005; Ali et al. 2010). With regard to the roles played by root VOCs in plant-plant interactions, only in vitro experiments have been performed to test the involvement of these compounds in interplant signalling (Ens et al. 2009; Jassbi et al. 2010). Because the experimental conditions do not reflect those found in a natural population (VOC concentrations, absence of soil, exposure of shoots to VOCs emitted by roots, etc.), this type of experiment has been criticized because it does not fully demonstrate the role of isolated chemicals in plant-plant interactions in nature (Inderjit and Dakshini 1995; Inderjit and Weston 2000; Inderjit and Callaway 2003; Inderjit and Nilsen 2003). Given these criticisms, several aspects of the experimental set-up need to be carefully addressed in order to test the implication of root-emitted VOCs in interplant signalling: (1) the ecological relevance of the biological model (do the emitter and receiver plants grow next to each other in a natural population?); (2) the developmental stages of the emitter and receiver plants used in the bioassays (how old are the emitter plants when they start synthesising and releasing VOCs? How old are the receiver plants when they start to be exposed to VOCs emitted by their neighbour in a natural population?); (3) the actual emission rates of VOCs released in the soil by unexcavated root systems; (4) the environmental factors modulating the emission of VOCs, (5) the environmental fate of VOCs in the rhizosphere; and (6) the possibility of differentiating the effects of volatile cues from that of resource competition. Because of their high vapour pressure at ambient temperatures, all the volatile compounds (VOCs and small inorganic volatiles such as $\mathrm{O}_{2}$ and $\mathrm{CO}_{2}$ ) located in a compartment containing one or more emitter plants can move to a second compartment containing one or more recipient plants. They can travel from one compartment to another either passively (Park et al. 2015) or actively using a purified airflow at a controlled flow rate (Ninkovic 2003; Ton et al. 2006). With regard to belowground biotic interactions, such systems have been used to expose the roots of $A$. thaliana plantlets to the volatiles released by a Gramnegative rhizobacteria (Serratia odorifera) cultivated in a liquid medium (Kai and Piechulla 2009) or to demonstrate the volatile-mediated growth promotion of tobacco plantlets (Nicotiana tabacum) by Pseudomonas fluorescens strain SS101 (Park et al. 2015). With these types of experimental devices, it is also possible to test the effects of particular VOCs on recipient plants using slow-release formulations of the pure chemical standards placed in the emitter compartment (Heuskin et al. 2011). When focusing on root-root interactions, the source of VOCs should be unexcavated root systems growing in a soil and, depending on the issues being investigated by the experimenter, roots can be submitted to biotic and/or abiotic stresses or left undamaged. Morphological (biomass production and allocation, root system architecture), physiological and/or molecular parameters can then be measured on plants that have been exposed to volatiles. Given that the roles played by root VOCs in interplant signalling have been far less studied than aboveground VOC-mediated plant-plant interactions, we would argue that the experimental devices described above can be modified in order to target root VOCs and investigate their ecological roles in interplant signalling (Fig. 3). 


\section{Conclusions}

Plant roots are able to synthesise and release a large number of organic compounds in the rhizosphere as solutes or volatile compounds that can diffuse at various distances from the source, depending on their physicochemical properties and environmental parameters (soil type, water content, microbial population, etc.). It is now well documented that root VOCs can act as signals mediating belowground biotic interactions between plants and organisms of the second and third trophic levels but, surprisingly, much less is known about their potential roles in between- and within-plant signalling (root-root and root-shoot). In this review, our aim was to show that root-root interactions mediated by volatile cues deserve more research attention and that the analytical tools and methods developed to explore volatilemediated plant-plant interactions aboveground can be adapted to investigate the roles played by VOCs in rootroot signalling. Given the growth in our knowledge about soil chemical ecology (van Dam 2014), particularly in relation with volatile-mediated biotic interactions, we conclude that future research in this area should include well-designed and ecologically relevant experiments aimed at investigating the roles played by root-emitted VOCs in between- and within-plant signalling.

Acknowledgments Delory $\mathrm{BM}$ was the recipient of a $\mathrm{PhD}$ Fellowship from the Belgian National Fund for Scientific Research. The drawings of this literature review were made by Carolina Levicek. The authors thank Nicole van Dam, Vicky Temperton, Hans Lambers, and three anonymous reviewers for their constructive comments on the manuscript.

\section{Compliance with ethical standards}

Conflict of interest The authors declare that they have no conflict of interest.

\section{References}

Abraham J, Giacomuzzi V, Angeli S (2015) Root damage to apple plants by cockchafer larvae induces a change in volatile signals below- and above-ground. Entomol Exp Appl 156: 279-289. doi:10.1111/eea. 12330

Abrahim D, Braguini WL, Kelmer-Bracht AM, Ishii-Iwamoto EL (2000) Effects of four monoterpenes on germination, primary root growth, and mitochondrial respiration of maize. J Chem Ecol 26:611-624

Abrahim D, Francischini AC, Pergo EM et al (2003) Effects of alpha-pinene on the mitochondrial respiration of maize seedlings. Plant Physiol Biochem 41:985-991. doi:10.1016/j. plaphy.2003.07.003

Ahman I, Ninkovic V (2010) Volatile interactions between undamaged plants: effects and potential for breeding resistance to aphids. In: Baluska F, Ninkovic V (eds) Plant Communication from an Ecological Perspective. Springer, pp 113-125

Ali JG, Alborn HT, Stelinski LL (2010) Subterranean herbivoreinduced volatiles released by Citrus roots upon feeding by Diaprepes abbreviatus recruit entomopathogenic nematodes. J Chem Ecol 36:361-368. doi:10.1007/s10886-010-9773-7

Ali JG, Alborn HT, Stelinski LL (2011) Constitutive and induced subterranean plant volatiles attract both entomopathogenic and plant parasitic nematodes. J Ecol 99:26-35. doi:10. 1111/j.1365-2745.2010.01758.x

Ali JG, Alborn HT, Campos-Herrera R et al (2012) Subterranean, herbivore-induced plant volatile increases biological control activity of multiple beneficial nematode species in distinct habitats. PLoS One 7, e38146. doi:10.1371/journal.pone. 0038146

Ali JG, Campos-Herrera R, Alborn HT et al (2013) Sending mixed messages: a trophic cascade produced by a belowground herbivore-induced cue. J Chem Ecol 39:1140-7. doi:10. 1007/s10886-013-0332-x

Arimura G, Ozawa R, Shimoda T et al (2000a) Herbivory-induced volatiles elicit defence genes in lima bean leaves. Nature 406: 512-515. doi:10.1038/35020072

Arimura G, Tashiro K, Kuhara S et al (2000b) Gene responses in bean leaves induced by herbivory and by herbivore-induced volatiles. Biochem Biophys Res Commun 277:305-310. doi: 10.1006/bbrc. 2000.3672

Arimura G, Ozawa R, Horiuchi J et al (2001) Plant-plant interactions mediated by volatiles emitted from plants infested by spider mites. Biochem Syst Ecol 29:1049-1061

Arimura G, Ozawa R, Nishioka T et al (2002) Herbivore-induced volatiles induce the emission of ethylene in neighboring lima bean plants. Plant J 29:87-98

Arimura G, Shiojiri K, Karban R (2010) Acquired immunity to herbivory and allelopathy caused by airborne plant emissions. Phytochemistry 71:1642-1649. doi:10.1016/j. phytochem.2010.06.021

Baldwin IT (2010) Plant volatiles. Curr Biol 20:392-397. doi:10. 1016/j.cub.2010.02.052

Baldwin IT, Schultz JC (1983) Rapid changes in tree leaf chemistry induced by damage: evidence for communication between plants. Science 221:277-278

Baldwin IT, Halitschke R, Paschold A et al (2006) Volatile signaling in plant-plant interactions: "talking trees" in the genomics era. Science 311:812-815

Ballaré CL (1999) Keeping up with the neighbors: phytochrome sensing and other signalling mechanisms. Trends Plant Sci 4: 97-102

Barney JN, Hay AG, Weston LA (2005) Isolation and characterization of allelopathic volatiles from mugwort (Artemisia vulgaris). J Chem Ecol 31:247-265. doi:10.1007/s10886005-1339-8 
Bate NJ, Rothstein SJ (1998) C6-volatiles derived from the lipoxygenase pathway induce a subset of defense-related genes. Plant J 16:561-569

Bertin C, Yang X, Weston LA (2003) The role of root exudates and allelochemicals in the rhizosphere. Plant Soil 256:67-83

Biedrzycki ML, Jilany TA, Dudley SA, Bais HP (2010) Root exudates mediate kin recognition in plants. Commun Integr Biol 3:28-35. doi:10.4161/cib.3.1.10118

Birkett MA, Campbell CAM, Chamberlain K et al (2000) New roles for cis-jasmone as an insect semiochemical and in plant defense. Proc Natl Acad Sci U S A 97:9329-9334. doi:10. 1073/pnas.160241697

Blande JD, Holopainen JK, Li T (2010) Air pollution impedes plant-to-plant communication by volatiles. Ecol Lett 13: 1172-1181. doi:10.1111/j.1461-0248.2010.01510.x

Boff MIC, Zoon FC, Smits PH (2001) Orientation of Heterorhabditis megidis to insect hosts and plant roots in a Y-tube sand olfactometer. Entomol Exp Appl 98:329-337

Boff MIC, van Tol R, Smits PH (2002) Behavioural response of Heterorhabditis megidis towards plant roots and insect larvae. Biocontrol 47:67-83

Bouwmeester HJ, Matusova R, Zhongkui S, Beale MH (2003) Secondary metabolite signalling in host-parasitic plant interactions. Curr Opin Plant Biol 6:358-364. doi:10.1016/ S1369-5266(03)00065-7

Bradow JM, Connick WJ (1990) Volatile seed-germination inhibitors from plant residues. J Chem Ecol 16:645-666

Bruin J, Sabelis MW, Dicke M (1995) Do plants tap SOS signals from their infested neighbours? Trends Ecol Evol 10:167170

Callaway RM (2002) The detection of neighbours by plants. Trends Ecol Evol 17:104-105

Callaway RM, Aschehoug ET (2000) Invasive plants versus their new and old neighbors: a mechanism for exotic invasion. Science 290:521-523. doi:10.1126/science.290.5491.521

Callaway RM, Ridenour WM (2004) Novel weapons: invasive success and the evolution of increased competitive ability. Front Ecol Environ 2:436-443

Campos-Herrera R, Ali JG, Diaz BM, Duncan LW (2013) Analyzing spatial patterns linked to the ecology of herbivores and their natural enemies in the soil. Front Plant Sci. doi:10. 3389/fpls.2013.00378

Chamberlain K, Guerrieri E, Pennacchio F et al (2001) Can aphidinduced plant signals be transmitted aerially and through the rhizosphere? Biochem Syst Ecol 29:1063-1074

Chen BJW, During HJ, Anten NPR (2012) Detect thy neighbor: Identity recognition at the root level in plants. Plant Sci 195: 157-167. doi:10.1016/j.plantsci.2012.07.006

Choh Y, Takabayashi J (2006) Herbivore-induced extrafloral nectar production in lima bean plants enhanced by previous exposure to volatiles from infested conspecifics. J Chem Ecol 32:2073-2077. doi:10.1007/s10886-006-9130-z

Choh Y, Shimoda T, Ozawa R et al (2004) Exposure of lima bean leaves to volatiles from herbivore-induced conspecific plants results in emission of carnivore attractants: active or passive process? J Chem Ecol 30:1305-1317

Cleveland CC, Yavitt JB (1998) Microbial consumption of atmospheric isoprene in a temperate forest soil. Appl Environ Microbiol 64:172-177

Crespo E, Hordijk CA, de Graaf RM et al (2012) On-line detection of root-induced volatiles in Brassica nigra plants infested with Delia radicum L. root fly larvae. Phytochemistry 84:6877. doi:10.1016/j.phytochem.2012.08.013

Danner H, Samudrala D, Cristescu SM, Van Dam NM (2012) Tracing hidden herbivores: time-resolved non-invasive analysis of belowground volatiles by proton-transfer-reaction mass spectrometry (PTR-MS). J Chem Ecol 38:785-794. doi:10.1007/s10886-012-0129-3

Danner H, Brown P, Cator EA et al (2015) Aboveground and belowground herbivores synergistically induce volatile organic sulfur compound emissions from shoots but not from roots. J Chem Ecol. doi:10.1007/s10886-015-0601-y

Das A, Lee S-H, Hyun TK et al (2013) Plant volatiles as method of communication. Plant Biotechnol Rep 7:9-26. doi:10.1007/ s11816-012-0236-1

de Albuquerque MB, dos Santos RC, Lima LM et al (2011) Allelopathy, an alternative tool to improve cropping systems. A review. Agron Sustain Dev 31:379-395. doi:10.1051/agro/ 2010031

de Kroon H (2007) How do roots interact? Science 318:15621563. doi:10.1126/science. 1150726

De Moraes CM, Lewis WJ, Paré PW et al (1998) Herbivoreinfested plants selectively attract parasitoids. Nature 393 : 570-573

De Moraes CM, Mescher MC, Tumlinson JH (2001) Caterpillarinduced nocturnal plant volatiles repel conspecific females. Nature 410:577-580

Degenhardt J, Hiltpold I, Köllner TG et al (2009) Restoring a maize root signal that attracts insect-killing nematodes to control a major pest. Proc Natl Acad Sci 106:13213-13218. doi:10.1073/pnas.0909073106

Demarta L, Hibbard BE, Bohn MO, Hiltpold I (2014) The role of root architecture in foraging behavior of entomopathogenic nematodes. J Invertebr Pathol. doi:10.1016/j.jip.2014.08.002

Depuydt S (2014) Arguments for and against self and non-self root recognition in plants. Front Plant Sci 5:1-7. doi:10.3389/fpls. 2014.00614

Dicke M, Bruin J (2001) Chemical information transfer between plants : back to the future. Biochem Syst Ecol 29:981-994

Dicke M, Dijkman H (2001) Within-plant circulation of systemic elicitor of induced defence and release from roots of elicitor that affects neighbouring plants. Biochem Syst Ecol 29: 1075-1087. doi:10.1016/S0305-1978(01)00051-5

Dicke M, Agrawal A, Bruin J (2003) Plants talk, but are they deaf? Trends Plant Sci 8:403-405. doi:10.1016/S1360-1385(03) 00183-3

Dolch R, Tscharntke T (2000) Defoliation of alders (Alnus glutinosa) affects herbivory by leaf beetles on undamaged neighbours. Oecologia 125:504-511. doi:10.1007/ s004420000482

Dudareva N, Negre F, Nagegowda DA, Orlova I (2006) Plant volatiles: recent advances and future perspectives. CRC Crit Rev Plant Sci 25:417-440. doi:10.1080/ 07352680600899973

Dudareva N, Klempien A, Muhlemann K, Kaplan I (2013) Biosynthesis, function and metabolic engineering of plant volatile organic compounds. New Phytol 198:16-32

Eilers EJ, Pauls G, Rillig MC et al (2015) Novel set-up for lowdisturbance sampling of volatile and non-volatile compounds from plant roots. J Chem Ecol 41:253-266. doi:10.1007/ s10886-015-0559-9 
Engelberth J, Alborn HT, Schmelz EA, Tumlinson JH (2004) Airborne signals prime plants against insect herbivore attack. Proc Natl Acad Sci U S A 101:1781-1785. doi:10.1073/ pnas.0308037100

Ens EJ, Bremner JB, French K, Korth J (2009) Identification of volatile compounds released by roots of an invasive plant, bitou bush (Chrysanthemoides monilifera spp. rotundata), and their inhibition of native seedling growth. Biol Invasions 11:275-287. doi:10.1007/s10530-008-9232-3

Erb M, Ton J, Degenhardt J, Turlings TC (2008) Interactions between arthropod-induced aboveground and belowground defenses in plants. Plant Physiol 146:867-874. doi:10.1104/ pp.107.112169

Erb M, Balmer D, De Lange ES et al (2011) Synergies and tradeoffs between insect and pathogen resistance in maize leaves and roots. Plant Cell Environ 34:1088-1103. doi:10.1111/j. 1365-3040.2011.02307.x

Erb M, Veyrat N, Robert CAM et al (2015) Indole is an essential herbivore-induced volatile priming signal in maize. Nat Commun. doi:10.1038/ncomms 7273

Faget M, Nagel KA, Walter A et al (2013) Root-root interactions: extending our perspective to be more inclusive of the range of theories in ecology and agriculture using in-vivo analyses. Ann Bot 112:253-266. doi:10.1093/aob/mcs296

Falik O, Reides P, Gersani M, Novoplansky A (2003) Self/nonself discrimination in roots. J Ecol 91:525-531. doi:10.1046/ j.1365-2745.2003.00795.x

Falik O, Mordoch Y, Quansah L et al (2011) Rumor has it...: relay communication of stress cues in plants. PLoS One 6, e23625. doi:10.1371/journal.pone.0023625

Falik O, Mordoch Y, Ben-Natan D et al (2012) Plant responsiveness to root-root communication of stress cues. Ann Bot 110: 271-280. doi:10.1093/aob/mcs045

Falik O, Hoffmann I, Novoplansky A (2014) Say it with flowers: flowering acceleration by root communication. Plant Signal Behav 9, e28258. doi:10.4161/psb.28258

Fang S, Clark RT, Zheng Y et al (2013) Genotypic recognition and spatial responses by rice roots. Proc Natl Acad Sci 110:26702675. doi:10.1073/pnas.1222821110

Farag M, Paré PW (2002) C6-green leaf volatiles trigger local and systemic VOC emissions in tomato. Phytochemistry 61:545554

Farmer EE (2001) Surface-to-air signals. Nature 411:854-856. doi:10.1038/35081189

Farmer EE, Ryan CA (1990) Interplant communication: airborne methyl jasmonate induces synthesis of proteinase inhibitors in plant leaves. Proc Natl Acad Sci U S A 87:7713-7716

Farmer EE, Johnson RR, Ryan CA (1992) Regulation of expression of proteinase inhibitor genes by methyl jasmonate and jasmonic acid. Plant Physiol 98:995-1002

Farnier K, Bengtsson M, Becher PG et al (2012) Novel bioassay demonstrates attraction of the white potato cyst nematode Globodera pallida (Stone) to non-volatile and volatile host plant cues. J Chem Ecol 38:795-801. doi:10.1007/s10886012-0105-y

Ferry A, Dugravot S, Delattre T et al (2007) Identification of a widespread monomolecular odor differentially attractive to several Delia radicum ground-dwelling predators in the field. J Chem Ecol 33:2064-2077. doi:10.1007/s10886-007-9373-3
Field B, Jordán F, Osbourn A (2006) First encounters - deployment of defence-related natural products by plants. New Phytol 172:193-207. doi:10.1111/j.1469-8137.2006.01863.x

Fiers M, Lognay G, Fauconnier M-L, Jijakli MH (2013) Volatile compound-mediated interactions between barley and pathogenic fungi in the soil. PLoS One 8, e66805. doi:10.1371/ journal.pone.0066805

Firn RD, Jones CG (1995) Plants may talk, but can they hear? Trends Ecol Evol 10:371

Fischer NH, Williamson GB, Weidenhamer JD, Richardson DR (1994) In search of allelopathy in the Florida scrub: the role of terpenoids. J Chem Ecol 20:1355-1380. doi:10.1007/ BF02059812

Fowler SV, Lawton JH (1985) Rapidly induced defenses and talking trees: the devil's advocate position. Am Nat 126: 181-195

Frost CJ, Appel HM, Carlson JE et al (2007) Within-plant signalling via volatiles overcomes vascular constraints on systemic signalling and primes responses against herbivores. Ecol Lett 10:490-498. doi:10.1111/j.1461-0248.2007.01043.x

Frost CJ, Mescher MC, Carlson JE, De Moraes CM (2008a) Why do distance limitations exist on plant-plant signaling via airborne volatiles? Plant Signal Behav 3:466-468. doi:10. 1111/j.1461-0248.2007.01043.x.466

Frost CJ, Mescher MC, Dervinis C et al (2008b) Priming defense genes and metabolites in hybrid poplar by the green leaf volatile cis-3-hexenyl acetate. New Phytol 180:722-734. doi:10.1111/j.1469-8137.2008.02599.x

Gersani M, Brown JS, O'Brien EE et al (2001) Tragedy of the commons as a result of root competition. J Ecol 89:660-669. doi:10.1046/j.0022-0477.2001.00609.x

Gfeller A, Laloux M, Barsics F et al (2013) Characterization of volatile organic compounds emitted by barley (Hordeum vulgare L.) roots and their attractiveness to wireworms. J Chem Ecol 39:1129-1139. doi:10.1007/s10886-013-0302-3

Girón-Calva PS, Molina-Torres J, Heil M (2012) Volatile dose and exposure time impact perception in neighboring plants. $\mathrm{J}$ Chem Ecol 38:226-228. doi:10.1007/s10886-012-0072-3

Glinwood R (2010) Volatile chemical interaction between undamaged plants: effects at higher trophic levels. In: Baluska F, Ninkovic V (eds) Plant Communication from an Ecological Perspective. Springer, pp 87-98

Glinwood R, Ninkovic V, Pettersson J, Ahmed E (2004) Barley exposed to aerial allelopathy from thistles (Cirsium spp.) becomes less acceptable to aphids. Ecol Entomol 29:188195

Glinwood R, Ahmed E, Qvarfordt E et al (2009) Airborne interactions between undamaged plants of different cultivars affect insect herbivores and natural enemies. Arthropod Plant Interact 3:215-224. doi:10.1007/s11829-009-9072-9

Glinwood R, Ninkovic V, Pettersson J (2011) Chemical interaction between undamaged plants - Effects on herbivores and natural enemies. Phytochemistry 72:1683-1689. doi:10.1016/j. phytochem.2011.02.010

Godard K-A, White R, Bohlmann J (2008) Monoterpene-induced molecular responses in Arabidopsis thaliana. Phytochemistry 69:1838-1849. doi:10.1016/j.phytochem. 2008.02.011

Gonkhamdee S, Pierret A, Maeght J-L et al (2010) Effects of corn (Zea mays $L$.) on the local and overall root development of 
young rubber tree (Hevea brasiliensis Muel. Arg). Plant Soil 334:335-351. doi:10.1007/s11104-010-0386-2

Gouinguené SP, Turlings TCJ (2002) The effects of abiotic factors on induced volatile emissions in corn plants. Plant Physiol 129:1296-1307. doi:10.1104/pp.001941.1296

Gruntman M, Novoplansky A (2004) Physiologically mediated self/non-self discrimination in roots. Proc Natl Acad Sci U S A 101:3863-3867. doi:10.1073/pnas.0306604101

Guerin PM, Ryan MF (1984) Relationship between root volatiles of some carrot cultivars and their resistance to the carrot fly, Psila rosae. Entomol Exp Appl 36:217-224

Guerrieri E, Poppy GM, Powell W et al (2002) Plant-to-plant communication mediating in-flight orientation of Aphidius ervi. J Chem Ecol 28:1703-1715

Haichar FEZ, Santaella C, Heulin T, Achouak W (2014) Root exudates mediated interactions belowground. Soil Biol Biochem 77:69-80. doi:10.1016/j.soilbio.2014.06.017

Heil M, Adame-Álvarez RM (2010) Short signalling distances make plant communication a soliloquy. Biol Lett 6:843-5. doi:10.1098/rsbl.2010.0440

Heil M, Karban R (2010) Explaining evolution of plant communication by airborne signals. Trends Ecol Evol 25:137-144. doi:10.1016/j.tree.2009.09.010

Heil M, Kost C (2006) Priming of indirect defences. Ecol Lett 9: 813-817. doi:10.1111/j.1461-0248.2006.00932.x

Heil M, Silva Bueno JC (2007) Within-plant signaling by volatiles leads to induction and priming of an indirect plant defense in nature. Proc Natl Acad Sci U S A 104:5467-5472. doi:10. 1073/pnas.0610266104

Heil M, Ton J (2008) Long-distance signalling in plant defence. Trends Plant Sci 13:264-272. doi:10.1016/j.tplants.2008.03. 005

Heuskin S, Verheggen FJ, Haubruge E et al (2011) The use of semiochemical slow-release devices in integrated pest management strategies. Biotechnol Agron Soc Environement 15: $459-470$

Hiltpold I, Turlings TCJ (2008) Belowground chemical signaling in maize: when simplicity rhymes with efficiency. J Chem Ecol 34:628-635. doi:10.1007/s10886-008-9467-6

Hiltpold I, Turlings TCJ (2012) Manipulation of chemically mediated interactions in agricultural soils to enhance the control of crop pests and to improve crop yield. J Chem Ecol 38:641650. doi:10.1007/s10886-012-0131-9

Hiltpold I, Baroni M, Toepfer S et al (2010a) Selection of entomopathogenic nematodes for enhanced responsiveness to a volatile root signal helps to control a major root pest. J Exp Biol 213:2417-2423. doi:10.1242/jeb.041301

Hiltpold I, Baroni M, Toepfer S et al (2010b) Selective breeding of entomopathogenic nematodes for enhanced attraction to a root signal did not reduce their establishment or persistence after field release. Plant Signal Behav 5:1450-1452

Hiltpold I, Toepfer S, Kuhlmann U, Turlings TCJ (2010c) How maize root volatiles affect the efficacy of entomopathogenic nematodes in controlling the western corn rootworm? Chemoecology 20:155-162. doi:10.1007/s00049-009-0034-6

Hiltpold I, Erb M, Robert CAM, Turlings TCJ (2011) Systemic root signalling in a belowground, volatile-mediated tritrophic interaction. Plant Cell Environ 34:1267-1275

Hiltpold I, Bernklau E, Bjostad LB, et al. (2013) Nature, evolution and characterisation of rhizospheric chemical exudates affecting root herbivores.
Holopainen JK (2004) Multiple functions of inducible plant volatiles. Trends Plant Sci 9:529-533. doi:10.1016/j.tplants.2004. 09.006

Holopainen JK, Blande JD (2012) Molecular plant volatile communication. Adv Exp Med Biol 739:17-31

Horiuchi J, Badri DV, Kimball BA et al (2007) The floral volatile, methyl benzoate, from snapdragon (Antirrhinum majus) triggers phytotoxic effects in Arabidopsis thaliana. Planta 226: 1-10. doi:10.1007/s00425-006-0464-0

Inderjit, Callaway RM (2003) Experimental designs for the study of allelopathy. Plant Soil 256:1-11. doi:10.1023/ A:1026242418333

Inderjit, Dakshini KMM (1995) On laboratory bioassays in allelopathy. Bot Rev 61:28-44

Inderjit, Duke SO (2003) Ecophysiological aspects of allelopathy. Planta 217:529-539. doi:10.1007/s00425-003-1054-z

Inderjit, Nilsen ET (2003) Bioassays and field studies for allelopathy in terrestrial plants: progress and problems. CRC Crit Rev Plant Sci 22:221-238. doi:10.1080/713610857

Inderjit, Weiner J (2001) Plant allelochemical interference or soil chemical ecology? Perspect Plant Ecol Evol Syst 4:3-12. doi: 10.1078/1433-8319-00011

Inderjit, Weston L (2000) Are laboratory bioassays for allelopathy suitable for prediction of field responses? J Chem Ecol 26: 2111-2118. doi:10.1023/A:1005516431969

Inderjit, von Dahl CC, Baldwin IT (2009) Use of silenced plants in allelopathy bioassays: a novel approach. Planta 229:569575. doi:10.1007/s00425-008-0856-4

Jassbi AR, Zamanizadehnajari S, Baldwin IT (2010) Phytotoxic volatiles in the roots and shoots of Artemisia tridentata as detected by headspace solid-phase microextraction and gas chromatographic-mass spectrometry analysis. J Chem Ecol 36:1398-1407. doi:10.1007/s10886-010-9885-0

Johnson D, Gilbert L (2015) Interplant signalling through hyphal networks. New Phytol 205:1448-1453. doi:10.1111/nph. 13115

Kai M, Piechulla B (2009) Plant growth promotion due to rhizobacterial volatiles - An effect of $\mathrm{CO}_{2}$ ? FEBS Lett 583: 3473-3477. doi:10.1016/j.febslet.2009.09.053

Karban R (2007) Experimental clipping of sagebrush inhibits seed germination of neighbours. Ecol Lett 10:791-797. doi:10. 1111/j.1461-0248.2007.01068.x

Karban R, Shiojiri K (2009) Self-recognition affects plant communication and defense. Ecol Lett 12:502-506

Karban R, Baldwin IT, Baxter KJ et al (2000) Communication between plants: induced resistance in wild tobacco plants following clipping of neighboring sagebrush. Oecologia 125:66-71

Karban R, Maron J, Felton GW et al (2003) Herbivore damage to sagebrush induces resistance in wild tobacco : evidence for eavesdropping between plants. Oikos 100:325-332

Karban R, Huntzinger M, McCall AC (2004) The specificity of eavesdropping on sagebrush by other plants. Ecology 85 : 1846-1852

Karban R, Shiojiri K, Huntzinger M, McCall AC (2006) Damageinduced resistance in sagebrush: volatiles are key to intra- and interplant communication. Ecology 87:922-930

Karban R, Shiojiri K, Ishizaki S (2011) Plant communication why should plants emit volatile cues? J Plant Interact 6:8184. doi:10.1080/17429145.2010.536589 
Karban R, Wetzel WC, Shiojiri K et al (2014a) Deciphering the language of plant communication: volatile chemotypes of sagebrush. New Phytol 204:380-385. doi:10.1111/nph. 12887

Karban R, Yang LH, Edwards KF (2014b) Volatile communication between plants that affects herbivory: a meta-analysis. Ecol Lett 17:44-52. doi:10.1111/ele.12205

Kegge W, Ninkovic V, Glinwood R et al (2015) Red:far-red light conditions affect the emission of volatile organic compounds from barley (Hordeum vulgare), leading to altered biomass allocation in neighbouring plants. Ann Bot. doi:10.1093/aob/ mev036

Kleinheinz GT, Bagley ST, St. John WP et al (1999) Characterization of alpha-pinene-degrading microorganisms and application to a bench-scale biofiltration system for VOC degradation. Arch Environ Contam Toxicol 37:151-157

Köllner TG, Schnee C, Gershenzon J, Degenhardt J (2004) The sesquiterpene hydrocarbons of maize (Zea mays) form five groups with distinct developmental and organ-specific distributions. Phytochemistry 65:1895-1902. doi:10.1016/j. phytochem.2004.05.021

Köllner TG, Held M, Lenk C et al (2008) A maize (E)-betacaryophyllene synthase implicated in indirect defense responses against herbivores is not expressed in most American maize varieties. Plant Cell 20:482-94. doi:10. $1105 /$ tpc. 107.051672

Kong CH, Hu F, Xu XH (2002) Allelopathic potential and chemical constituents of volatiles from Ageratum conyzoides under stress. J Chem Ecol 28:1173-1182

Koocheki A, Lalegani B, Hosseini SA (2013) Ecological consequences of allelopathy. In: Cheema ZA, Farooq M, Wahid A (eds) Allelopathy - Current Trends and Future Applications. Springer, New York, pp 23-38

Kost C, Heil M (2006) Herbivore-induced plant volatiles induce an indirect defence in neighbouring plants. J Ecol 94:619628. doi:10.1111/j.1365-2745.2006.01120.x

Lawo NC, Weingart GJF, Schuhmacher R, Forneck A (2011) The volatile metabolome of grapevine roots: first insights into the metabolic response upon phylloxera attack. Plant Physiol Biochem 49:1059-1063. doi:10.1016/j.plaphy.2011.06.008

Laznik Ž, Košir IJ, Rozman L et al (2011) Preliminary results of variability in mechanical-induced volatile root-emissions of different maize cultivars. Maydica 56:343-350

Li T, Holopainen JK, Kokko H et al (2012) Herbivore-induced aspen volatiles temporally regulate two different indirect defences in neighbouring plants. Funct Ecol. doi:10.1111/j. 1365-2435.2012.01984.x

Lin C, Owen SM, Penuelas J (2007) Volatile organic compounds in the roots and rhizosphere of Pinus spp. Soil Biol Biochem 39:951-960. doi:10.1016/j.soilbio.2006.11.007

Loreto F, Schnitzler J-P (2010) Abiotic stresses and induced BVOCs. Trends Plant Sci 15:154-166. doi:10.1016/j. tplants.2009.12.006

Maffei ME (2010) Sites of synthesis, biochemistry and functional role of plant volatiles. South African J Bot 76:612-631. doi: 10.1016/j.sajb.2010.03.003

Mahall BE, Callaway RM (1991) Root communication among desert shrubs. Proc Natl Acad Sci U S A 88:874-876. doi:10. 1073/pnas.88.3.874

Matsui K, Minami A, Hornung E et al (2006) Biosynthesis of fatty acid derived aldehydes is induced upon mechanical wounding and its products show fungicidal activities in cucumber. Phytochemistry 67:649-657. doi:10.1016/j. phytochem.2006.01.006

Misra G, Pavlostathis SG, Perdue EM, Araujo R (1996) Aerobic biodegradation of selected monoterpenes. Appl Microbiol Biotechnol 45:831-838

Mohney BK, Matz T, LaMoreaux J et al (2009) In situ silicone tube microextraction: a new method for undisturbed sampling of root-exuded thiophenes from Marigold (Tagetes erecta L.) in soil. J Chem Ecol 35:1279-1287. doi:10.1007/ s10886-009-9711-8

Neveu N, Grandgirard J, Nenon JP, Cortesero AM (2002) Systemic release of herbivore-induced plant volatiles by turnips infested by concealed root-feeding larvae Delia radicum L. J Chem Ecol 28:1717-1732

Ninkovic V (2003) Volatile communication between barley plants affects biomass allocation. J Exp Bot 54:1931-1939. doi:10. 1093/jxb/erg 192

Ninkovic V (2010) Volatile interaction between undamaged plants: a short cut to coexistence. In: Baluska F, Ninkovic $\mathrm{V}$ (eds) Plant Communication from an Ecological Perspective, Springer. pp 75-86

Ninkovic V, Pettersson J (2003) Searching behaviour of the sevenspotted ladybird, Coccinella septempunctata - effects of plant-plant odour interaction. Oikos 100:65-70

Ninkovic V, Glinwood R, Dahlin I (2009) Weed-barley interactions affect plant acceptance by aphids in laboratory and field experiments. Entomol Exp Appl 133:38-45. doi:10.1111/j. 1570-7458.2009.00900.x

Nishida N, Tamotsu S, Nagata N et al (2005) Allelopathic effects of volatile monoterpenoids produced by Salvia leucophylla: inhibition of cell proliferation and DNA synthesis in the root apical meristem of Brassica campestris seedlings. J Chem Ecol 31:1187-1203. doi:10.1007/s10886-005-4256-y

Owen SM, Clark S, Pompe M, Semple KT (2007) Biogenic volatile organic compounds as potential carbon sources for microbial communities in soil from the rhizosphere of Populus tremula. FEMS Microbiol Lett 268:34-39. doi:10. 1111/j.1574-6968.2006.00602.x

Palma R, Mutis A, Manosalva L et al (2012) Behavioral and electrophysiological responses of Hylastinus obscurus to volatiles released from the roots of Trifolium pratense L. J Soil Sci Plant Nutr 12:183-193

Park S-W, Kaimoyo E, Kumar D et al (2007) Methyl salicylate is a critical mobile signal for plant systemic acquired resistance. Science 318:113-116. doi:10.1126/science.1147113

Park Y-S, Dutta S, Ann M et al (2015) Promotion of plant growth by Pseudomonas fluorescens strain SS101 via novel volatile organic compounds. Biochem Biophys Res Commun 461: 361-365. doi:10.1016/j.bbrc.2015.04.039

Paschold A, Halitschke R, Baldwin IT (2006) Using “mute" plants to translate volatile signals. Plant J 45:275-291. doi:10.1111/ j.1365-313X.2005.02623.x

Peñuelas J, Asensio D, Tholl D et al (2014) Biogenic volatile emissions from the soil. Plant Cell Environ 37:1866-1891. doi: 10.1111 pce. 12340

Perry LG, Alford ER, Horiuchi J et al (2007) Chemical signals in the rhizosphere: root-root and root-microbe communication. In: Pinton R, Varanini Z, Nannipieri P (eds) The rhizosphere: biochemistry and organic substances at the soil-plant interface. CRC Press, Boca Raton, pp 297-330 
Pettersson J, Ninkovic V, Ahmed E (1999) Volatiles from different barley cultivars affect aphid acceptance of neighbouring plants. Acta Agric Scand Sect B-Soil Plant Sci 49:152-157

Pierik R, Visser EJW, De Kroon H, Voesenek LACJ (2003) Ethylene is required in tobacco to successfully compete with proximate neighbours. Plant Cell Environ 26:1229-1234. doi:10.1046/j.1365-3040.2003.01045.x

Plhak F, Urbankova V (1969) Study of the effect of volatile substances from cereal roots. Biol Plant 11:226-235

Preston CA, Laue G, Baldwin IT (2001) Methyl jasmonate is blowing in the wind, but can it act as a plant-plant airborne signal ? Biochem Syst Ecol 29:1007-1023

Ramirez KS, Lauber CL, Fierer N (2009) Microbial consumption and production of volatile organic compounds at the soillitter interface. Biogeochemistry 99:97-107. doi:10.1007/ s10533-009-9393-x

Rasmann S, Turlings TCJ (2007) Simultaneous feeding by aboveground and belowground herbivores attenuates plantmediated attraction of their respective natural enemies. Ecol Lett 10:926-936. doi:10.1111/j.1461-0248.2007.01084.x

Rasmann S, Turlings TCJ (2008) First insights into specificity of belowground tritrophic interactions. Oikos 117:362-369. doi:10.1111/j.2007.0030-1299.16204.x

Rasmann S, Köllner TG, Degenhardt J et al (2005) Recruitment of entomopathogenic nematodes by insect-damaged maize roots. Nature 434:732-737. doi:10.1038/nature03451

Rasmann S, Erwin AC, Halitschke R, Agrawal AA (2011) Direct and indirect root defences of milkweed (Asclepias syriaca): trophic cascades, trade-offs and novel methods for studying subterranean herbivory. J Ecol 99:16-25. doi:10.1111/j. 1365-2745.2010.01713.x

Rasmann S, Hiltpold I, Ali J (2012) The role of root-produced volatile secondary metabolites in mediating soil interactions. In: Montanaro G, Bartolomeo D (eds) Advances in Selected Plant Physiology Aspects. InTech, Rijeka, pp 269-290

Rhoades DF (1983) Responses of alder and willow to attack by tent caterpillars and webworms: evidence for pheromonal sensitivity of willows. In: Hedin PA (ed) Plant resistance to insects, American C. Washington, DC, pp 55-68

Robert CAM, Erb M, Duployer M et al (2012a) Herbivoreinduced plant volatiles mediate host selection by a root herbivore. New Phytol 194:1061-1069. doi:10.1111/j.14698137.2012.04127.x

Robert CAM, Erb M, Hibbard BE et al (2012b) A specialist root herbivore reduces plant resistance and uses an induced plant volatile to aggregate in a density-dependent manner. Funct Ecol 26:1429-1440. doi:10.1111/j.1365-2435.2012.02030.x

Robert CAM, Erb M, Hiltpold I, et al. (2013a) Genetically engineered maize plants reveal distinct costs and benefits of constitutive volatile emissions in the field. Plant Biotechnol J 1-12. doi: 10.1111/pbi.12053

Robert CAM, Frank DL, Leach K et al (2013b) Direct and indirect plant defenses are not suppressed by endosymbionts of a specialist root herbivore. J Chem Ecol 39:507-515. doi:10. 1007/s10886-013-0264-5

Rodriguez-Saona CR, Rodriguez-Saona LE, Frost CJ (2009) Herbivore-induced volatiles in the perennial shrub, Vaccinium corymbosum, and their role in inter-branch signaling. J Chem Ecol 35:163-175. doi:10.1007/s10886-0089579-z
Romagni JG, Allen SN, Dayan FE (2000) Allelopathic effects of volatile cineoles on two weedy plant species. J Chem Ecol 26:303-313

Rostás M, Cripps MG, Silcock P (2015) Aboveground endophyte affects root volatile emission and host plant selection of a belowground insect. Oecologia 177:487-497. doi:10.1007/ s00442-014-3104-6

Ruiz J, Bilbao R, Murillo MB (1998) Adsorption of different VOC onto soil minerals from gas phase: influence of mineral, type of VOC, and air humidity. Environ Sci Technol 32:10791084

Runyon JB, Mescher MC, De Moraes CM (2006) Volatile chemical cues guide host location and host selection by parasitic plants. Science 313:1964-1967. doi:10.1126/science. 1131371

Ruther J, Kleier S (2005) Plant-plant signaling: ethylene synergizes volatile emission in Zea mays induced by exposure to (Z)-3-hexen-1-ol. J Chem Ecol 31:2217-2222. doi:10. 1007/s10886-005-6413-8

Schenkel D, Lemfack MC, Piechulla B, Splivallo R (2015) A meta-analysis approach for assessing the diversity and specificity of belowground root and microbial volatiles. Front Plant Sci 6:1-11. doi:10.3389/fpls.2015.00707

Schmid C, Bauer S, Bartelheimer M (2015) Should I stay or should I go? Roots segregate in response to competition intensity. Plant Soil 391:283-291. doi:10.1007/s11104-0152419-3

Semchenko M, Saar S, Lepik A (2014) Plant root exudates mediate neighbour recognition and trigger complex behavioural changes. New Phytol 204:631-637

Shirey RE (1999) SPME fibers and selection for specific applications. In: Scheppers Wercinski SA (ed) Solid phase microextraction: a practical guide. Marcel Dekker, Inc., New York, pp 59-110

Shulaev V, Silverman P, Raskin I (1997) Airborne signalling by methyl salicylate in plant pathogen resistance. Nature 385 : 718-721

Simard SW, Perry DA, Jones MD et al (1997) Net transfer of carbon between ectomycorrhizal tree species in the field. Nature 388:579-582

Singh HP, Batish DR, Kohli RK (2002) Allelopathic effect of two volatile monoterpenes against bill goat weed (Ageratum conyzoides L.). Crop Prot 21:347-350

Singh HP, Batish DR, Setia N, Kohli RK (2005) Herbicidal activity of volatile oils from Eucalyptus citriodora against Parthenium hysterophorus. Ann Appl Biol 146:89-94

Singh HP, Batish DR, Kaur S et al (2006) Alpha-pinene inhibits growth and induces oxidative stress in roots. Ann Bot 98: 1261-1269. doi:10.1093/aob/mcl213

Sohrabi R, Huh J-H, Badieyan S et al (2015) In planta variation of volatile biosynthesis: an alternative biosynthetic route to the formation of the pathogen-induced volatile homoterpene DMNT via triterpene degradation in Arabidopsis roots. Plant Cell 27:874-890. doi:10.1105/tpc.114.132209

Song YY, Zeng SR, Xu JF (2010) Interplant communication of tomato plants through underground common mycorrhizal networks. PLoS One 5:e13324. doi:10.1371/journal.pone. 0013324

Steeghs M, Bais HP, de Gouw J et al (2004) Proton-transferreaction mass spectrometry as a new tool for real time analysis of root-secreted volatile organic compounds in 
Arabidopsis. Plant Physiol 135:47-58. doi:10.1104/pp.104. 038703

Sugimoto K, Matsui K, Iijima Y et al (2014) Intake and transformation to a glycoside of $(Z)$-3-hexenol from infested neighbors reveals a mode of plant odor reception and defense. Proc Natl Acad Sci U S A 111:7144-7149. doi:10.1073/pnas. 1320660111

Sutherland OR, Hillier J (1974) Olfactory response of Costelytra zealandica (Coleoptera: Melolonthinae) to the roots of several pasture plants. New Zeal J Zool 1:365-369

Tapia T, Perich F, Pardo F et al (2007) Identification of volatiles from differently aged red clover (Trifolium pratense) root extracts and behavioural responses of clover root borer (Hylastinus obscurus) (Marsham) (Coleoptera : Scolytidae) to them. Biochem Syst Ecol 35:61-67. doi:10.1016/j.bse. 2006.05.020

Tholl D, Boland W, Hansel A et al (2006) Practical approaches to plant volatile analysis. Plant J 45:540-560. doi:10.1111/j. 1365-313X.2005.02612.X

Ton J, D'Alessandro M, Jourdie Vet al (2006) Priming by airborne signals boosts direct and indirect resistance in maize. Plant $\mathrm{J}$ 49:16-26. doi:10.1111/j.1365-313X.2006.02935.x

Tscharntke T, Thiessen S, Dolch R, Boland W (2001) Herbivory, induced resistance, and interplant signal transfer in Alnus glutinosa. Biochem Syst Ecol 29:1025-1047

Turlings TCJ, Tumlinson JH, Lewis WJ (1990) Exploitation of herbivore-induced plant odors by host-seeking parasitic wasps. Science 250:1251-1253. doi:10.1126/science. 250 . 4985.1251

Turlings TCJ, Hiltpold I, Rasmann S (2012) The importance of root-produced volatiles as foraging cues for entomopathogenic nematodes. Plant Soil 358:51-60. doi:10.1007/s11104012-1295-3

Unsicker SB, Kunert G, Gershenzon J (2009) Protective perfumes: the role of vegetative volatiles in plant defense against herbivores. Curr Opin Plant Biol 12:479-485. doi:10.1016/j.pbi. 2009.04.001

van Dam NM (2014) Plant chemical ecology finally gets to its root(s). J Chem Ecol 40:220-221. doi:10.1007/s10886-0140401-9

van Dam NM, Samudrala D, Harren FJM, Cristescu SM (2012) Real-time analysis of sulfur-containing volatiles in Brassica plants infested with root-feeding Delia radicum larvae using proton-transfer reaction mass spectrometry. AoB Plants 2012:pls021. doi: 10.1093/aobpla/pls021 van Tol R, van der Sommen ATC, Boff MIC et al (2001) Plants protect their roots by alerting the enemies of grubs. Ecol Lett 4:292-294

Walker TS, Bais HP, Grotewold E, Vivanco JM (2003) Root exudation and rhizosphere biology. Plant Physiol 132:44 51. doi:10.1104/pp.102.019661

Weissteiner S, Schutz S (2006) Are different volatile pattern influencing host plant choice of belowground living insects? In: Papers from the Entomological Conference in Dresden, Germany, 21-24 March 2005. Deutsche Gesellschaft fur allgemeine und angewandte Entomologie e.V., pp 51-55

Weissteiner S, Huetteroth W, Kollmann M et al (2012) Cockchafer larvae smell host root scents in soil. PLoS One 7, e45827. doi:10.1371/journal.pone.0045827

Wenda-Piesik A, Piesik D, Ligor T, Buszewski B (2010) Volatile organic compounds (VOCs) from cereal plants infested with crown rot: their identity and their capacity for inducing production of VOCs in uninfested plants. Int J Pest Manag 56:377-383. doi:10.1080/09670874.2010.505668

Wenke K, Kai M, Piechulla B (2010) Belowground volatiles facilitate interactions between plant roots and soil organisms. Planta 231:499-506. doi:10.1007/s00425-009-1076-2

Weston LA, Ryan PR, Watt M (2012) Mechanisms for cellular transport and release of allelochemicals from plant roots into the rhizosphere. J Exp Bot 63:3445-3454. doi:10.1093/jxb/ ers054

Witcosky JJ, Schowalter TD, Hansen EM (1987) Host-derived attractants for the beetles Hylastes nigrinus (Coleoptera: Scotylidae) and Steremnius carinatus (Coleoptera: Curculionidae). Environ Entomol 16:1310-1313

Yan Z-G, Wang C-Z (2006) Wound-induced green leaf volatiles cause the release of acetylated derivatives and a terpenoid in maize. Phytochemistry 67:34-42. doi:10.1016/j.phytochem. 2005.10.005

Yi H-S, Heil M, Adame-Alvarez RM et al (2009) Airborne induction and priming of plant defenses against a bacterial pathogen. Plant Physiol 151:2152-2161. doi:10.1104/pp.109. 144782

Zeng SR (2014) Allelopathy - The solution is indirect. J Chem Ecol 40:515-516. doi:10.1007/s10886-014-0464-7

Zhang Y, Ruyter-Spira C, Bouwmeester HJ (2015) Engineering the plant rhizosphere. Curr Opin Biotechnol 32:136-142. doi:10.1016/j.copbio.2014.12.006

Zunino MP, Zygadlo JA (2004) Effect of monoterpenes on lipid oxidation in maize. Planta 219:303-309. doi:10.1007/ s00425-004-1216-7 